ARTICLE

DOI: $10.1038 / \mathrm{s} 41467-017-01019-z$

\title{
Fructose-1,6-bisphosphate couples glycolytic flux to activation of Ras
}

Ken Peeters ${ }^{1,2}$, Frederik Van Leemputte ${ }^{1,2}$, Baptiste Fischer (10 3,4, Beatriz M. Bonini ${ }^{1,2}$, Hector Quezada (10) 1,2, Maksym Tsytlonok ${ }^{3,4}$, Dorien Haesen ${ }^{5}$, Ward Vanthienen ${ }^{1,2}$, Nuno Bernardes (1) 1,2, Carmen Bravo Gonzalez-Blas (1D 1,2, Veerle Janssens (DD ${ }^{5}$, Peter Tompa ${ }^{3,4}$, Wim Versées ${ }^{3,4}$

\& Johan M. Thevelein (1D 1,2

Yeast and cancer cells share the unusual characteristic of favoring fermentation of sugar over respiration. We now reveal an evolutionary conserved mechanism linking fermentation to activation of Ras, a major regulator of cell proliferation in yeast and mammalian cells, and prime proto-oncogene product. A yeast mutant (tps1 $1 \Delta$ ) with overactive influx of glucose into glycolysis and hyperaccumulation of Fru1,6bisP, shows hyperactivation of Ras, which causes its glucose growth defect by triggering apoptosis. Fru1,6bisP is a potent activator of Ras in permeabilized yeast cells, likely acting through Cdc25. As in yeast, glucose triggers activation of Ras and its downstream targets MEK and ERK in mammalian cells. Biolayer interferometry measurements show that physiological concentrations of Fru1,6bisP stimulate dissociation of the pure Sos1/H-Ras complex. Thermal shift assay confirms direct binding to Sos1, the mammalian ortholog of $\mathrm{Cdc} 25$. Our results suggest that the Warburg effect creates a vicious cycle through Fru1,6bisP activation of Ras, by which enhanced fermentation stimulates oncogenic potency.

\footnotetext{
${ }^{1}$ Laboratory of Molecular Cell Biology, Institute of Botany and Microbiology, KU Leuven, Kasteelpark Arenberg 31, Leuven-Heverlee, Flanders B-3001, Belgium. ${ }^{2}$ Center for Microbiology, VIB, Kasteelpark Arenberg 31, Leuven-Heverlee, Flanders B-3001, Belgium. ${ }^{3}$ VIB-VUB Center for Structural Biology, Pleinlaan 2, Brussels 1050, Belgium. ${ }^{4}$ Structural Biology Brussels (SBB), Vrije Universiteit Brussel, Pleinlaan 2, Brussels 1050, Belgium. ${ }^{5}$ Laboratory of Protein Phosphorylation and Proteomics, Department of Cellular and Molecular Medicine, KU Leuven, Gasthuisberg O\&N1, Herestraat 49, Leuven 3000, Belgium. Ken Peeters, Frederik Van Leemputte and Baptiste Fischer contributed equally to this work. Correspondence and requests for materials should be addressed to J.M.T. (email: johan.thevelein@kuleuven.vib.be)
} 
Y east is one of the most prominent examples of eukaryotic cells, which displays under aerobic conditions high fermentative activity as well as rapid cell proliferation, just like mammalian cancer cells ${ }^{1}$. Warburg suggested that high glycolytic activity may be causally related to the cancerous state ${ }^{2}$, while in yeast high glycolytic activity also correlates with the most rapid cell proliferation. There is a striking correlation between the rate of uncontrolled cell proliferation, the aggressive metastasis character of cancers and the extent of the 'Warburg effect' ${ }^{3,4}$. In spite of many studies, however, it remains controversial whether strong fermentation is a cause or a symptom of cancer since no clear molecular link between glycolysis and proteins controlling cell proliferation has been identified ${ }^{5}$.

Yeast and mammalian cells also share the G-protein and oncogene product, Ras, with a homologous set of regulators, Cdc25,Sdc25/Sos1 and Ira1,2/NF1, but with different target proteins, adenylate cyclase in yeast and, e.g., the Raf protein kinase in mammalian cells ${ }^{6-8}$. Ras is highly conserved. Mammalian Ras can functionally replace yeast $\operatorname{Ras}^{9}$ and hyperactive Ras oncogenes cause aberrant cell proliferation control and apoptosis induction in yeast $\mathrm{t}^{10,11}$. Mutant $R A S$ genes, encoding overactive (permanently GTP loaded) Ras proteins, are among the most common oncogenes found in naturally occurring and artificially induced cancer cells ${ }^{12}$. Ras also serves as an important regulator of cell proliferation in yeast acting through activation of cAMP synthesis and the protein kinase A (PKA) pathway (Fig. 1$)^{6}$. Glucose is a potent activator of CAMP synthesis and thus of protein kinase $\mathrm{A}$
(PKA) in yeast, and this is mediated by Cdc25/Ras in concert with a glucose-sensing G-protein coupled receptor system (Fig. 1) ${ }^{13-}$ 18. Glucose catabolism in glycolysis is required for cAMP signaling and activation of the Ras proteins (Fig. 1) ${ }^{15,19}$ but the underlying mechanism has been unclear. The strong conservation of Ras and its regulators, Cdc25,Sdc25/Sos1 and Ira1,2/NF1, in yeast and mammalian cells, suggests that the unknown mechanism responsible for glycolytic activation of Ras may also be conserved in the two cell types.

In nearly all cells, glucose is phosphorylated by hexokinase or glucokinase to glucose-6-phosphate (Glu6P) after its transport into the cells, then converted to fructose-6-phosphate (Fru6P) by phosphoglucoisomerase and subsequently phosphorylated to Fru1,6bisP by phosphofructokinase 1 (Fig. 1). Fru1,6bisP is by far the most elaborately controlled glycolytic metabolite since its biosynthetic and hydrolytic enzymes are post-translationally controlled by multiple mechanisms, including a specific allosteric regulator, Fru2,6bisP, which is synthesized and hydrolyzed in a parallel regulatory pathway ${ }^{20}$. Fru1,6bisP is split into the triose phosphates dihydroxyacetone phosphate (DHAP) and glyceraldehyde-3-phosphate (GAP), which are ultimately converted into pyruvate, and further into a fermentation product, either ethanol in yeast (Fig. 1) or lactic acid in mammalian cells.

Multiple molecular changes have been identified in cancer cells contributing to the high glycolytic rate, including enhanced intrinsic activity of phosphofructokinase 1 and higher levels of its allosteric activator Fru2,6bis $\mathrm{P}^{3,21,22}$. Hexokinase activity has also

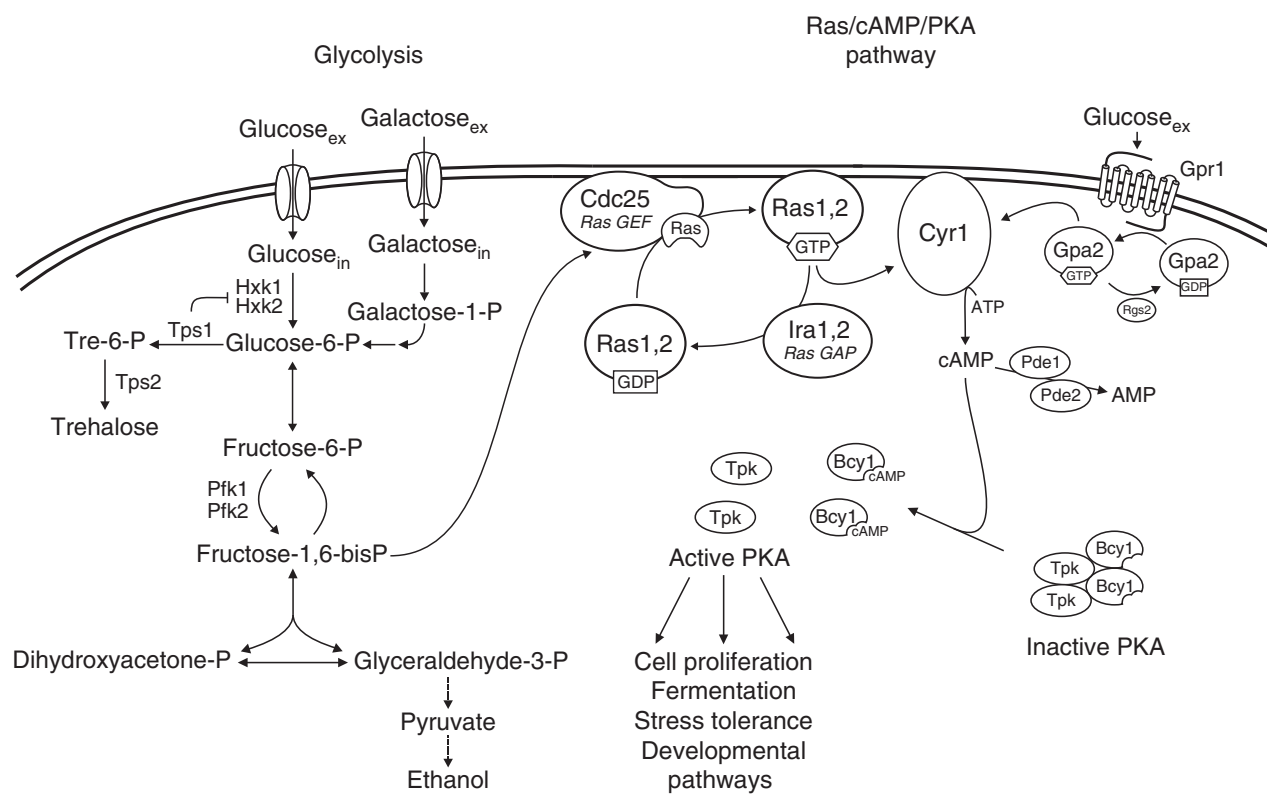

Fig. 1 Schematic overview of initial glucose metabolism in yeast and its connection to activation of the Ras-cAMP-PKA pathway. Extracellular glucose is transported by facilitated diffusion into the cells after which it is phosphorylated by one of the two hexokinases or by glucokinase. The activity of the two hexokinases, but not glucokinase, is feedback-inhibited by Tre6P, the intermediate in trehalose biosynthesis. Glu6P is further converted into Fru6P, Fru1,6bisP, the triose phosphates DHAP and GAP, and the latter is subsequently converted to pyruvate and the fermentation product ethanol. Galactose is taken up by its own carrier, phosphorylated to Gal1P and further converted into Glu6P, where it joins the glucose catabolic pathway, effectively bypassing the hexokinase catalyzed step in glycolysis. The Ras-cAMP-PKA pathway exerts major control over cell proliferation, fermentation rate, stress tolerance and developmental pathways in yeast. As in mammalian cells, cAMP is synthesized by adenylate cyclase (Cyr1) and binds to the Bcy1 regulatory subunits of PKA, causing their dissociation from the catalytic Tpk subunits with activation of the latter as result. Yeast adenylate cyclase is activated by a glucosesensing G-protein coupled receptor (GPCR) system, composed of the Gpr1 receptor, the Go protein Gpa2, and its GAP factor Rgs2, similar to activation of adenylate cyclase by GPCR systems in mammalian cells. As opposed to mammalian cells, however, yeast adenylate cyclase is also activated by the Ras1,2 proteins, which are controlled by the Cdc25 (and Sdc25) guanine nucleotide exchange factor (GEF) and the GTPase activating proteins (GAP) Ira1,2. Ras and its regulators are highly conserved between yeast and mammalian cells (the GEF Sos and the GAP NF1, respectively). Although it was known that glucose catabolism in glycolysis is required for glucose activation of the Ras proteins and cAMP synthesis, the molecular connection remained unknown. In the present paper, it is shown that Fru1,6bisP functions as activator of Ras by interacting with $\mathrm{Cdc} 25$ and that this connection between glycolysis and Ras is conserved between yeast and mammalian cells 
a
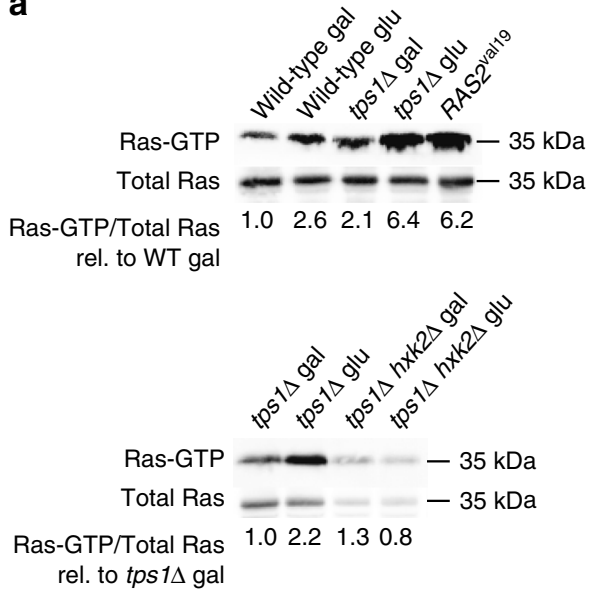

c

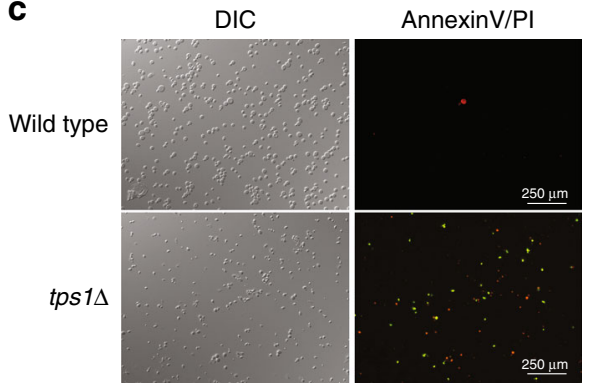

b
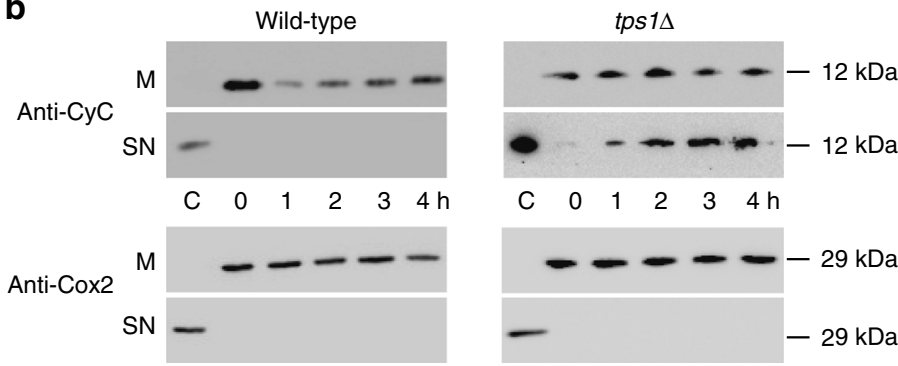

d

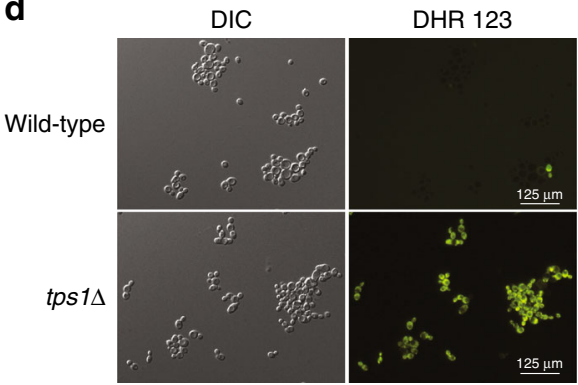

Fig. 2 Glucose triggers activation of Ras and apoptosis in tps1 $\Delta$ cells. a Ras-GTP level before and 10 min after addition of glucose (glu) to cells grown on galactose (gal). The strain expressing Ras ${ }^{\text {val19 }}$ was grown on glucose. Total Ras = Ras-GDP + Ras-GTP. Quantification of the signals as Ras-GTP level/total Ras level compared to the ratio for wild type or $\operatorname{tps} 1 \Delta$ on galactose set at 1.0. The values were determined through quantification by densitometry and are expressed as relative arbitrary units. b Specific cytochrome $\mathrm{c}$ release from the mitochondria after addition of glucose to wild type and tps $1 \Delta$ strain. $M$, mitochondrial fraction; SN, post-mitochondrial supernatant; Anti-CyC, anti-cytochrome c antibody; Anti-Cox2, cytochrome oxidase 2 antibody; C: control cytochrome c or cytochrome oxidase 2. c Annexin-V-FITC/propidium iodide staining $2 \mathrm{~h}$ after addition of glucose to cells grown on galactose. Green colored fluorescence originates from annexin staining, red colored fluorescence represents propidium iodide binding to DNA of death cells. The scale bar is $250 \mu \mathrm{m}$. d Reactive oxygen species (ROS) accumulation $2 \mathrm{~h}$ after addition of glucose to cells grown on galactose. ROS was stained with the dye dihydrorhodamine 123. DIC, differential interference contrast image. The scale bar is $125 \mu \mathrm{m}$

received particular attention as one of the major determinants of the Warburg effect. In certain types of cancer cells, type II hexokinase is strongly associated with the mitochondrial ADP/ATP carrier, losing its feedback inhibition by glucose-6P and allowing much higher catalytic activity due to efficient coupling with mitochondrial ATP provision ${ }^{3}$. When such cancer cells were grown on galactose, a sugar whose metabolism does not involve hexokinase, the high fermentation rate was strongly reduced ${ }^{23}$. Subsequent work showed that this alteration of type II hexokinase was sufficient to enhance the glycolytic rate of a normal cell up to that observed in cancer cells ${ }^{24}$. Extensive additional evidence has highlighted the critical role of type II hexokinase in aberrant glycolytic metabolism of cancer cells ${ }^{3}$.

Whereas mammalian hexokinase is feedback-inhibited by its product Glu6 $\mathrm{P}^{25}$, yeast hexokinase is feedback inhibited by trehalose-6-phosphate (Tre6P) (Fig. 1) ${ }^{26}$. Tre6P is synthesized from Glu6P and UDPG by Tre6P synthase (Tps1) as intermediate of trehalose biosynthesis (Fig. 1). Tps1 $1 \Delta$ cells have unbridled hexokinase activity and display uncontrolled influx of glucose into glycolysis ${ }^{27}$. This is characterized by hyperaccumulation of metabolites upstream of glyceraldehyde-3-phosphate dehydrogenase (GAPDH) in the upper part of glycolysis, especially Fru1,6bisP, and rapid depletion of ATP, phosphate and glycolytic metabolites downstream of GAPDH. As a result the tps1 $1 \Delta$ strain is unusually sensitive to low amounts (a few mM) of glucose se, $29^{2}$. Deletion of hexokinase 2, the most active hexokinase isoenzyme in yeast, completely suppresses aberrant glucose catabolism and restores growth on glucose of the $t p s 1 \Delta$ strain $^{30}$. Since galactose metabolism uses galactokinase rather than hexokinase for conversion of galactose into Glu6P and entry at this point into glycolysis, tps1 $1 \Delta$ cells do not show deregulated glycolysis with galactose as substrate and grow normally on galactose. Hence, in a certain sense, $t p s 1 \Delta$ cells resemble cancer cells with unrestricted hexokinase activity, although their fermentation defect is much more severe, causing complete absence of growth on glucose.

In the present work, we have made use of the yeast tps $1 \Delta$ mutant to identify the molecular connection between glucose fermentation and activation of Ras. We provide extensive evidence for an evolutionary conserved mechanism between yeast and mammalian cells in which Fru1,6bisP functions in physiological concentrations as a potent activator of the Ras proteins, acting through its Cdc25/Sos1 guanine nucleotide exchange factor. This finding suggests that the Warburg effect, i.e., the elevated fermentation rate in cancer cells, creates a vicious cycle through Fru1,6bisP activation of Ras, causing enhanced fermentation rate to stimulate oncogenic potency.

\section{Results}

Glucose triggers apoptosis through Ras. We show that glucose addition to galactose-grown tps $1 \Delta$ cells triggers rapid and dramatic activation of Ras, as opposed to the modest activation observed in wild type cells (Fig. 2a). The GTP loading state on Ras in the tps $1 \Delta$ strain, 10 min after glucose addition, is similar to 
that in a strain expressing the constitutively active Ras $2^{\text {val19 }}$ oncogene equivalent (Fig. 2a). A Ras $2^{\text {val19 }}$ strain, however, has no detectable growth inhibition on glucose medium ${ }^{10}$. Deletion of hexokinase 2 abolishes glucose-induced hyperactivation of Ras (Fig. 2a), which is consistent with its complete suppression of the glucose growth defect of the tps $1 \Delta$ strain $^{30}$. Whereas the Ras $2^{\text {val19 }}$
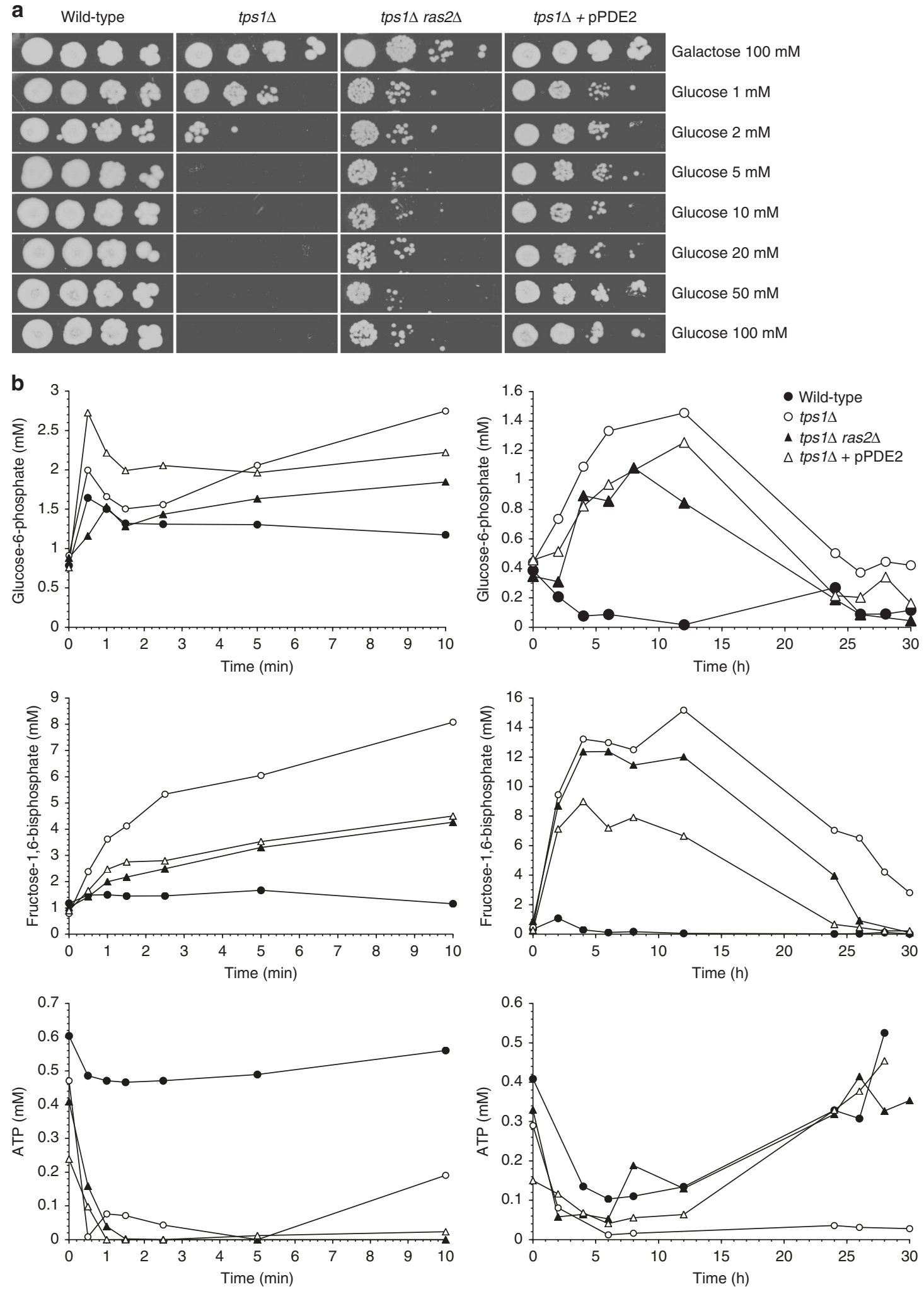

Fig. 3 Restoration of growth on glucose and glycolytic metabolite levels in the tps $1 \Delta$ strain with downregulation of the Ras-cAMP-PKA pathway. a Growth of $\operatorname{tps} 1 \Delta$ and suppressor strains on galactose and different concentrations of glucose. Five-fold dilutions were spotted. $\mathbf{b}$ Intracellular Glu6P, Fru1,6bisP and ATP concentration before and after addition of $100 \mathrm{mM}$ glucose. The short-term measurements $(0-10 \mathrm{~min})$ were performed with non-growing cells incubated in $25 \mathrm{mM}$ MES buffer ( $\mathrm{pH}$ 6.0), while the long-term measurements (0-30 h) were performed with cells growing in minimal galactose medium 
a

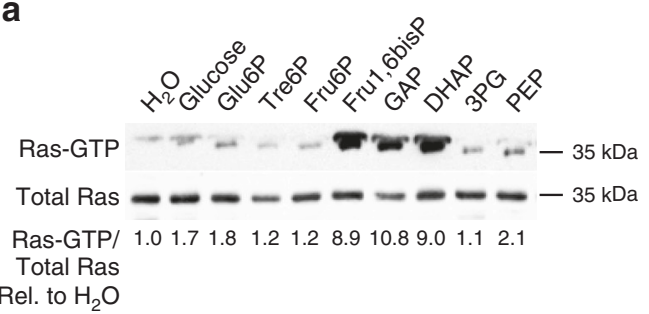

b

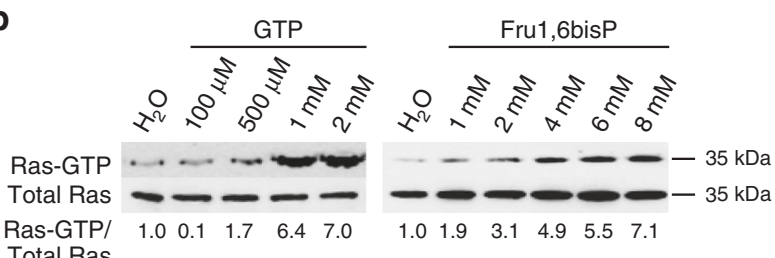

Rel. to $\mathrm{H}_{2} \mathrm{O}$

C

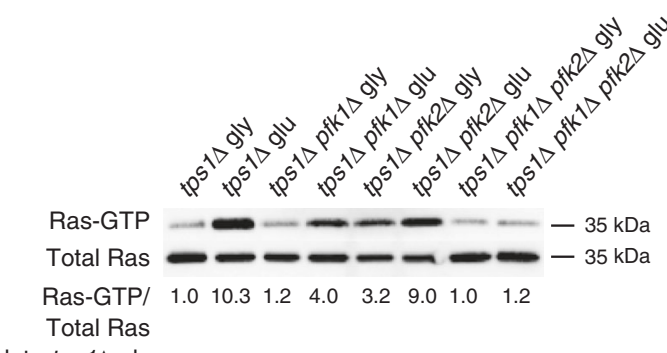

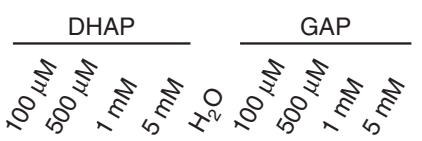

Ras-GTP _ _ _ _ _ _ - $35 \mathrm{kDa}$

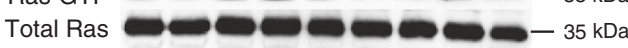

$\begin{array}{llllllllll}\text { Ras-GTP/ } & 0.5 & 0.3 & 1.4 & 1.8 & 1.0 & 1.0 & 1.1 & 3.2 & 2.3\end{array}$

Total Ras

Rel. to $\mathrm{H}_{2} \mathrm{O}$

Rel. to tps $1 \Delta$ gly
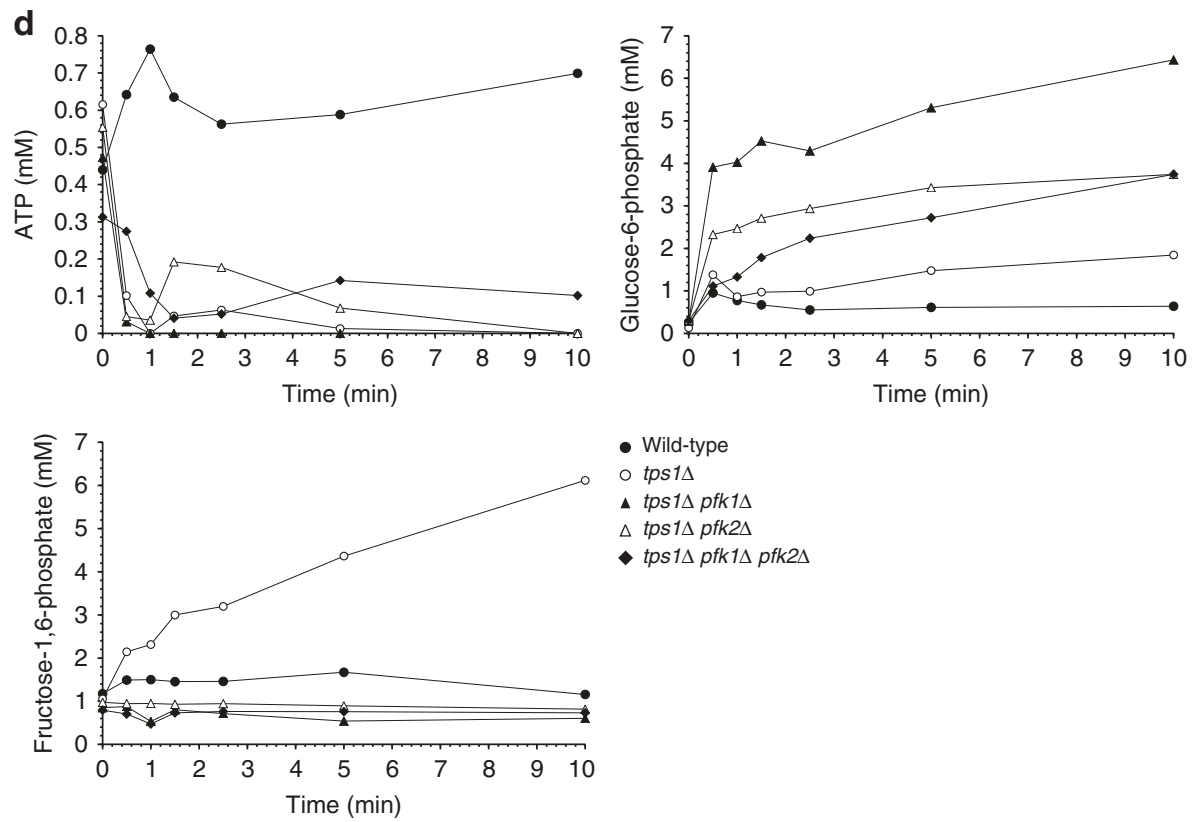

- Wild-type

- tps $1 \Delta$

$\Delta$ tps $1 \Delta$ pfk $1 \Delta$

$\Delta$ tps $1 \Delta$ pfk2 $2 \Delta$

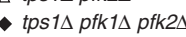

Fig. 4 Activation of Ras by Fru1,6bisP. a Ras-GTP level 3 min after addition of $5 \mathrm{mM}$ of different glycolytic metabolites to permeabilized yeast spheroplasts. Glu6P, glucose-6-phosphate; Tre6P, trehalose-6-phosphate; Fru6P, fructose-6-phosphate; Fru1,6bisP, fructose-1,6-bisphosphate; DHAP, dihydroxyacetone phosphate; GAP, glyceraldehyde-3-phosphate; 3PG, 3-phosphoglycerate; PEP, phosphoenolpyruvate. Quantification of the signals as Ras-GTP level/total Ras level compared to the ratio for the water control set at 1.0. The values were determined through quantification by densitometry and are expressed as relative arbitrary units. b Activation of Ras in permeabilized spheroplasts with different concentrations of GTP, Fru1,6bisP, DHAP and GAP. Quantification of the signals as Ras-GTP level/total Ras level compared to the ratio for the water control set at 1.0. The values were determined through quantification by densitometry and are expressed as relative arbitrary units. c Ras-GTP level before and 10 min after addition of 100 mM glucose (glu) to cells grown on glycerol $+2.5 \mathrm{mM}$ glucose (gly). Quantification of the signals as Ras-GTP level/total Ras level compared to the ratio for tps1 $\Delta$ on glycerol set at 1.0 . The values were determined through quantification by densitometry and are expressed as relative arbitrary units. d Intracellular ATP, Glu6P, and Fru1,6bisP concentration before and after addition of $100 \mathrm{mM}$ glucose to cells grown in glycerol $+2.5 \mathrm{mM}$ glucose

strain shows normal growth on glucose, it grows with strongly reduced rate on poor carbon sources, like galactose, and dies in stationary phase $\mathrm{e}^{10}$. More recent work has shown that hyperactive Ras causes programmed cell death/apoptosis in non-growing yeast cells ${ }^{11}$. Hence, we reasoned that the combination of aberrant growth initiation due to the glycolytic deregulation and hyperactivation of Ras in tps $1 \Delta$ cells may cause apoptosis and that this actually might be the real cause for the unusually high glucose sensitivity of $t p s 1 \Delta$ cells ${ }^{29}$ rather than the deregulation of glycolysis per se. Determination of classical read-outs for apoptosis in yeast gave results consistent with this hypothesis. Glucose addition to tps1 $1 \Delta$ cells, as opposed to wild type cells, caused rapid release of cytochrome $c$ from the mitochondria (Fig. 2b), exposure of phosphatidylserine at the plasma membrane (Fig. 2c) and generation of reactive oxygen species (ROS) (Fig. 2d). These results are consistent with recent evidence that the Tps1 protein acts as an anti-apoptotic factor in yeast ${ }^{31}$. The drop in the cytochrome $c$ level in the wild-type cells might be caused by glucose repression of the CYC1 gene ${ }^{32}$. It is absent in the tps $1 \Delta$ strain because that strain is deficient in glucose-induced 
a

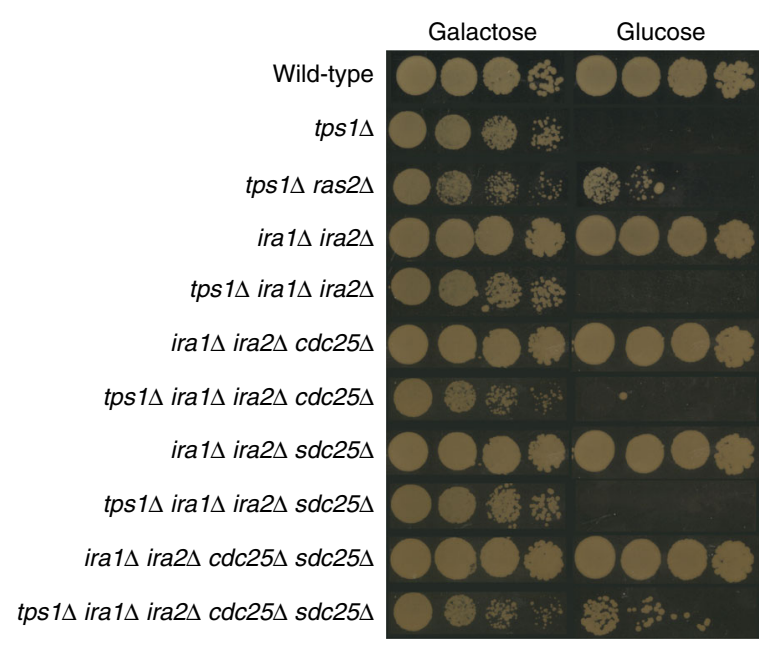

b

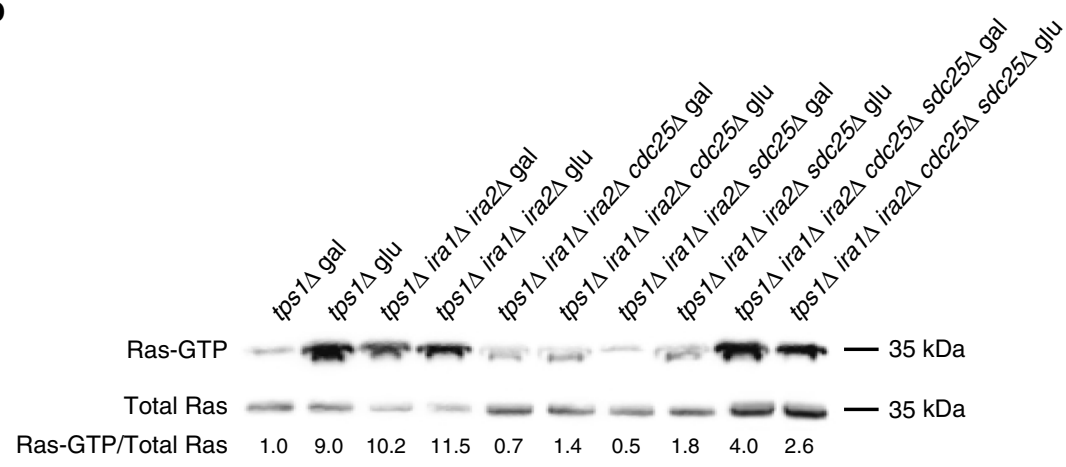

Rel. to $t p s 1 \Delta$ gal

C

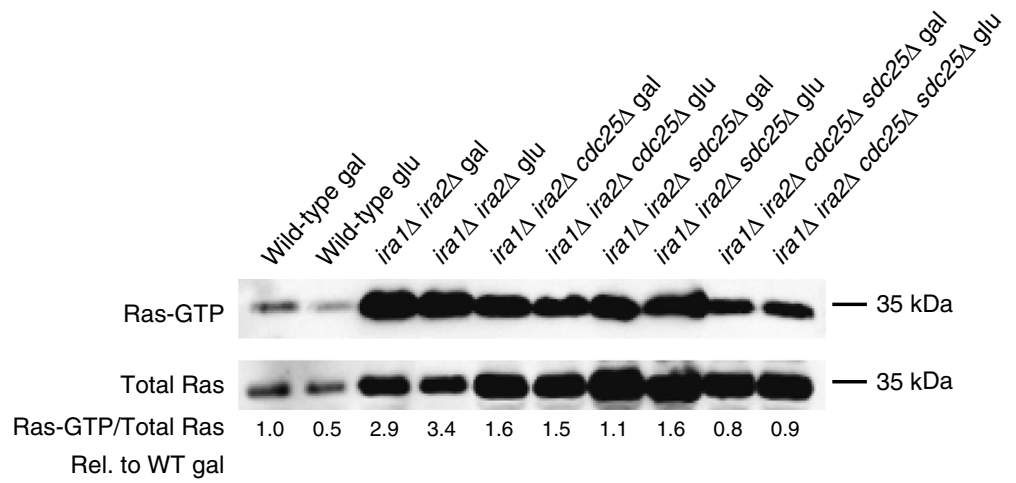

Fig. 5 Evaluation of requirement for the GEF and GAP regulators of Ras. a Growth on galactose and glucose. Five-fold dilutions were spotted. b, c Ras-GTP level before and $10 \mathrm{~min}$ after addition of glucose ( $\mathrm{glu}$ ) to cells grown on galactose (gal). Quantification of the signals as Ras-GTP level/total Ras level compared to the ratio for wild type (b) or $\operatorname{tps} 1 \Delta$ (c) on galactose set at 1.0. The values were determined through quantification by densitometry and are expressed as relative arbitrary units

signaling ${ }^{28}$. The inability to detect a decrease in the cytochrome $c$ content of the mitochondria in the tps $1 \Delta$ strain concomitant with the appearance of cytochrome $c$ in the supernatant, is likely due to the fact that the amount appearing in the supernatant is much smaller than the amount remaining in the mitochondria.

Deletion of Ras 2 in the tps $1 \Delta$ strain caused partial recovery of growth on glucose (Fig. 3a). Overexpression of PDE2, which encodes the high-affinity cAMP phosphodiesterase and is known to counteract phenotypes caused by hyperactive Ras ${ }^{33}$, restored growth on glucose even better (on solid medium: Fig. 3a; in liquid medium: Supplementary Fig. 1). This may be due to the fact that overexpression of Pde2 lowers the cAMP level in the cells even more than deletion of Ras 2 and thus leads to lower PKA activity.
Our results are consistent with overactive Ras playing a role in the glucose growth defect of the tps $1 \Delta$ strain. Interestingly, both in the $t p s 1 \Delta$ and $t p s 1 \Delta$ ras $2 \Delta$ strain a very similar deregulation of glycolysis after addition of glucose was present, including hyperaccumulation of Fru1,6bisP and depletion of ATP, but the metabolite profile started to recover in the tps $1 \Delta$ ras $2 \Delta$ strain after about $5 \mathrm{~h}$ to finally reach the same profile as observed in wild type cells (Fig. 3b). The difference was most striking in the ATP level, which stayed close to zero in the tps $1 \Delta$ strain, but recovered to the same level as in wild type cells in the tps $1 \Delta$ ras $2 \Delta$ and tps $1 \triangle \mathrm{p} P D E 2$ strains (Fig. 3b). This indicates remarkable robustness and flexibility of the glycolytic pathway in yeast and contradicts that the strong perturbation of metabolite 
homeostasis is causing the glucose growth defect. The results suggest that the induction of programmed cell death, caused by overactivation of the Ras-cAMP-PKA pathway, is the true cause of the inability of the $t p s 1 \Delta$ strain to grow on glucose, rather than the glycolytic deregulation, which is usually thought to be the main cause ${ }^{34}$. The onset of the normalization of glycolytic metabolite homeostasis a few hours after addition of glucose in the $t p s 1 \triangle$ ras $2 \Delta$ and tps $1 \triangle \mathrm{p} P D E 2$ strains (Fig. $3 \mathrm{~b}$ ) might suggest that an additional time-dependent change in initial glucose catabolism occurs, which allows the cells to recover normal glycolytic flux and intermediate levels.

Fru1,6bisP triggers activation of Ras. To investigate whether one or more of the hyperaccumulated glycolytic metabolites in the tps $1 \Delta$ strain acted as the trigger for hyperactivation of Ras, we made use of nystatin-permeabilized wild type yeast spheroplasts ${ }^{35}$. These are cells of which the cell wall has been largely removed and the plasma membranes permeabilized to allow passage of all small molecules. Because of their fragility the permeabilized cell sacs were not washed and the small molecules leaked into the medium were thus only strongly diluted. Addition of glycolytic metabolites to permeabilized spheroplasts revealed strong activation of Ras by Fru1,6bisP at the higher physiological concentrations (4-8 mM; Fig. $4 \mathrm{a}, \mathrm{b}$ ), similar to that observed with physiological concentrations of GTP (Fig. 4b). DHAP and GAP also caused activation but only in unphysiologically high concentrations (1-5 mM; Fig. 4a, b). Other glycolytic intermediates, and glucose or Tre6P did not cause activation (Fig. 4a).

To evaluate whether Fru1,6bisP is responsible for glucoseinduced hyperactivation of Ras in the tps $1 \Delta$ strain, we constructed tps $1 \Delta$ strains with additional single or double deletion of the PFK1 and PFK2 genes, encoding phosphofructokinase 1 . Glucose-induced activation of Ras was reduced in cells of the $t p s 1 \Delta p f k 1 \Delta$ and $t p s 1 \Delta p f k 2 \Delta$ strains, and abolished in cells

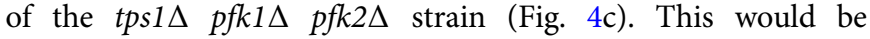
consistent with the hyperaccumulation of Frul,6bisP in tps $1 \Delta$ cells being responsible for hyperactivation of Ras. However, upon measurement of the glycolytic metabolites, the $t p s 1 \Delta p f k 1 \Delta$ and $t p s 1 \Delta p f k 2 \Delta$ strains were already deficient in glucose-induced hyperaccumulation of Fru1,6bisP and consistently showed a much higher accumulation of Glu6P than the tps $1 \Delta$ strain (Fig. $4 \mathrm{~d}$ ). Glu6P was also higher than in the corresponding $p f k 1 \Delta$ and $p f k 2 \Delta$ strains (Fig. $4 \mathrm{~d}$ ).

The presence of partial Ras activation without Fru1,6bisP accumulation in the tps $1 \Delta p f k 1 \Delta$ and $t p s 1 \Delta p f k 2 \Delta$ strains suggests that there may be a second mechanism responsible for glucose-induced hyperactivation of Ras in the tps $1 \Delta$ strain and/or that the hyperaccumulation of Glu6P in these strains in some way triggers a residual activation. Although the complete absence of Ras hyperactivation in the tps $1 \Delta p f k 1 \Delta p f k 2 \Delta$ strain seems to contradict this possibility, the very poor growth of this strain, requiring feeding with both a respiratory carbon source and a low level of glucose, may have compromised the second activation mechanism. It can also not be excluded that one of the glucose signaling pathways modifies $\mathrm{Cdc} 25$, for instance through phosphorylation, to render it more sensitive to Fru1,6bisP. This could explain why even in the absence of an increase in the level of Fru1,6bisP, it would still be able to trigger activation of Ras after addition of glucose.

Fru1,6bisP acts through the Ras GEF Cdc25 in yeast. We next investigated whether Fru1,6bisP caused direct activation of Ras or acted through one of its regulators, the guanine nucleotide exchange proteins Cdc25 and Sdc25, or the GTPase activating proteins Ira1 and Ira2. For that purpose we constructed several strains with combinations of tps $1 \Delta$ and deletions in the genes encoding these regulators. Deletion of both CDC25 and SDC25 is lethal ${ }^{36}$, while deletion of IRA1 and IRA2 causes hyperactivation of $\operatorname{Ras}^{37}$. The ira1 $\Delta$ ira2 $\Delta c d c 25 \Delta s d c 25 \Delta$ strain retains enough Ras activity for growth (Fig. 5a). All quadruple tps $1 \Delta$ strains with at least one wild-type GEF factor, Cdc25, or Sdc25, were unable to grow on glucose, whereas absence of both GEF factors in the quintuple deletion strain tps $1 \Delta$ cdc25 $s d c 25 \Delta$ ira1 $\Delta$ ira $2 \Delta$ restored to some extent growth on glucose medium (Fig. $5 \mathrm{a}$, Supplementary Fig. 2). This suggests that glucose-induced hyperactivation of Ras through the GEF factors is a major cause of the glucose sensitivity of the tps $1 \Delta$ strain. The tps $1 \Delta$ ira1 $\Delta$ ira $2 \Delta$ strain showed already a high Ras-GTP level on galactose medium, which made it difficult to evaluate any further glucose-induced increase (Fig. 5b). On the other hand, in the quadruple deletion strains, $t p s 1 \Delta s d c 25 \Delta$ ira $1 \Delta$ ira $2 \Delta$ and $t p s 1 \Delta$ $c d c 25 \Delta$ ira $1 \Delta$ ira $2 \Delta$, the rapid glucose-induced hyperactivation of Ras was largely abolished, indicating requirement of both GEF factors. The absence of Ras hyperactivation in these strains may be restricted to the short-term response, since both strains were still unable to grow on glucose (Fig. 5a). Unexpectedly, we found that the quintuple deletion strain, $t p s 1 \Delta c d c 25 \Delta s d c 25 \Delta$ ira $1 \Delta$ ira $2 \Delta$, showed a higher basal activity of Ras on galactose medium, which, however, did not increase further upon addition of glucose (Fig. 5b). Although these experiments and the interpretation of the results are complicated because of the essential character of the GEF factors, the high basal Ras activity caused by deletion of the GAP proteins, and the unexpectedly higher basal level of RasGTP in the quintuple deletion strain, the results are consistent with a role of the GEF factors in mediating glucose-induced hyperactivation of Ras in the $t p s 1 \Delta$ strain. This was confirmed by the observation that deletion of SDC25 and especially CDC25 in the tps $1 \Delta$ strain caused partial growth recovery on glucose (Supplementary Fig. 3). This result also suggests that Fru1,6bisP exerts its activating effect mainly through Cdc25.

We have also performed similar experiments in the wild-type strain background. This confirmed the much weaker and more variable glucose-induced activation of Ras in the wild type strain (which may be due to transient oscillation in the response; Fig. 5 c). Deletion of IRA1 and IRA2 caused a dramatic increase in Ras-GTP both in galactose and glucose incubated cells (Fig. 5c), which made it impossible to evaluate reliably any possible further increase in Ras-GTP in the presence of glucose. Deletion of $C D C 25$ or SDC25 caused a partial reduction of the very high RasGTP level, while double deletion of CDC25 and SDC25 caused a further reduction in the Ras-GTP level (Fig. 5c). In none of the latter strains was a significant difference between the galactose and glucose condition observed, consistent with the idea that the glucose activation effect on Ras acts through its Cdc25 and Sdc25 GEF factors.

Since previous work had shown that the highly conserved C terminus of Cdc25 was required for glucose activation of cAMP synthesis ${ }^{38,39}$, we focused on this part of Cdc25 to identify amino acid residues of which mutagenesis might abolish Fru1,6bisP activation of Ras in permeabilized spheroplasts and also restore growth of the tpsis mutant on glucose. We selected for site-directed mutagenesis a highly conserved region with several positively charged residues (Fig. 6a) (aa 1478-1501 in Cdc25) that could possibly be involved in the formation of a binding site for the negatively charged Fru1,6bisP molecule. Interestingly, another positively charged residue, $\mathrm{R} 1122$ in yeast Cdc25, which corresponds to K602 in human Sos1, resides in the vicinity of this region in the $3 \mathrm{D}$ structure of the human Sos1 catalytic domain $^{40}$. The R1122/K602 residue is located itself in a small conserved region. Figure 6 a shows the $3 \mathrm{D}$ structure of Sos 1 in 
association with Ras and the position in space of selected amino acid residues in the cleft formed by the alpha helix I of Sos1 and the switch 1 region of Ras, thus in the area where the two proteins interact. The amino acid residues K602, R962, and K963 of Sos1, are located within this cleft (Fig. 6a).

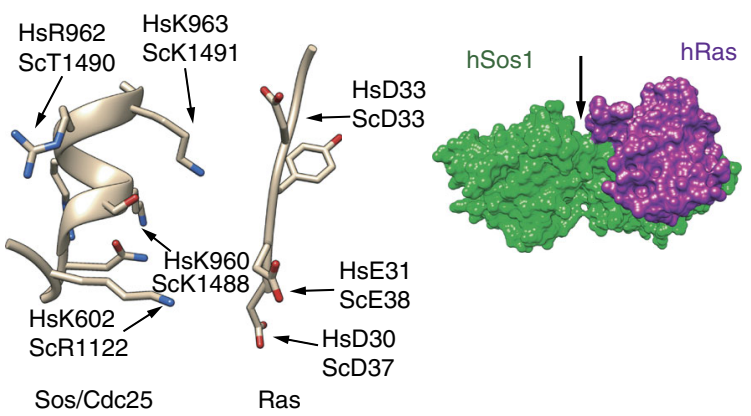

C

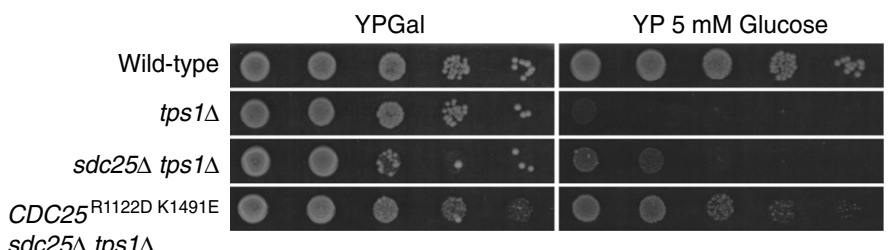
$s d c 25 \Delta \operatorname{tps} 1 \Delta$

HsSos1 RHGKEL I NF SKRRKVAE I TGE I QQ AA 950-973 HsSos2 KKGKDL I NF S KRRK VAE I TGE I QQ AA 948-971 ScCdc25 HNSTN I I NFSKRTK I AN I VEE I I S AA 1478-1501 ScSdc25 HDEKKY I NFNKRSRLVD I LQE I I Y AA 931-954

b
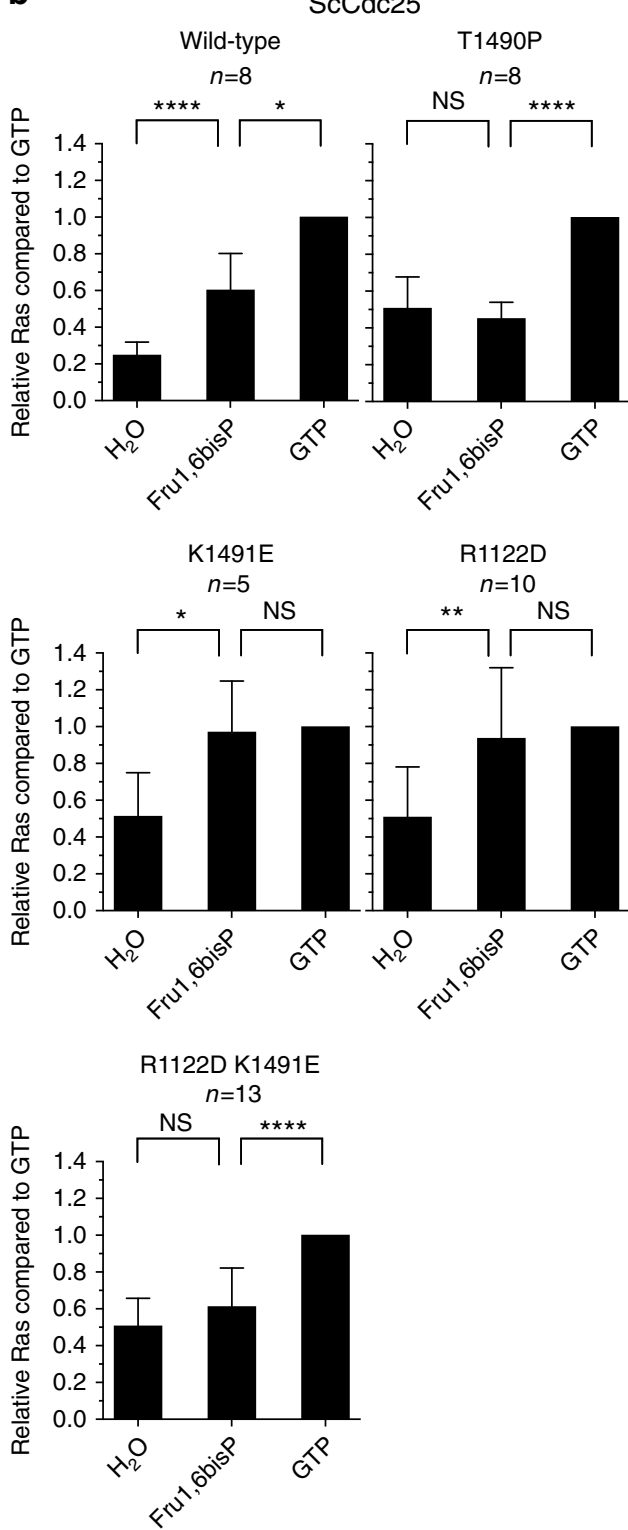

d

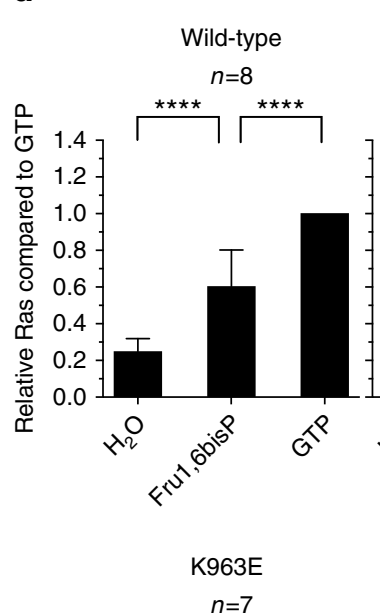

HsSos1

R962T

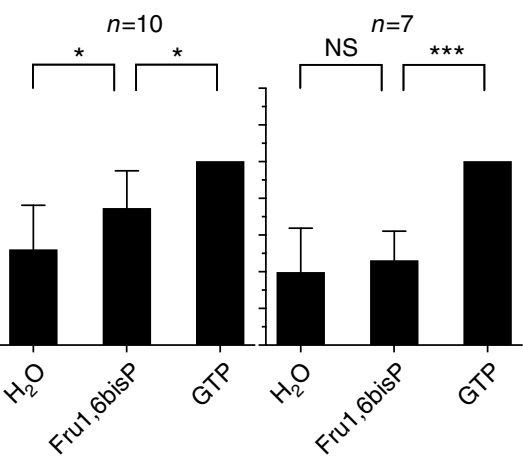

K602E K963E

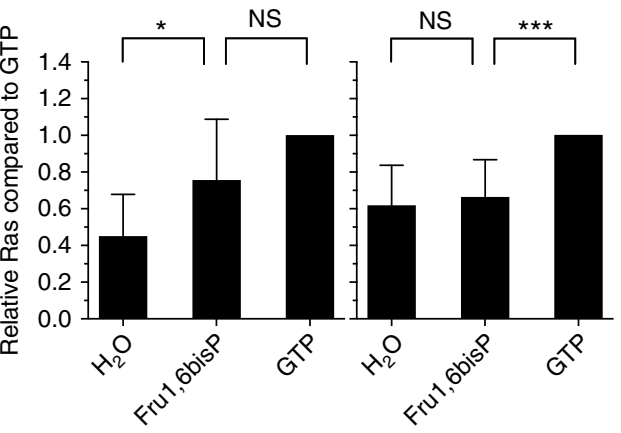

Fig. 6 Conserved residues in the $\mathrm{C}$ terminus of $\mathrm{Cdc} 25$ and Sos1 are required for Fru1,6bisP activation of Ras. a Alignment of the conserved region in the Ras GEF factors, HsSos1 and HsSos2 from Homo sapiens and ScCdc25 and ScSdc25 from Saccharomyces cerevisiae. Crystal structure of the complex between human Sos1 (green) and human Ras (purple) (PD entry: $1 B K D^{40}$ ). The arrow points to the cleft, which contains the conserved region. Enlarged view on the 3D structure surrounding the relevant residues in Sos1 and Cdc25 located in the conserved region. $\mathbf{b}$, d Ras-GTP level 3 min after addition of $5 \mathrm{mM}$ Fru1,6bisP or $1 \mathrm{mM}$ GTP as positive control, to permeabilized yeast spheroplasts from strains expressing mutant ScCdc25 (b) or HsSos1 (d) alleles. Western blots were quantified and the Ras-GTP levels are shown relative to the level observed after addition of GTP. Values represent average (number of replicates shown above each graph), error bars represent standard deviations. Sidak's multiple comparison test was used for evaluation of statistical significance ((NS) identifies $p$-values greater than $0.05,\left({ }^{\star}\right)$ identifies $p$-values between 0.01 and $0.05,\left({ }^{\star \star}\right)$ between 0.01 and 0.001 , $\left({ }^{\star \star \star}\right)$ between 0.001 and 0.0001, $\left.{ }^{(\star \star \star}\right)$ identifies p-values lower than 0.0001). c Recovery of growth on glucose in the tps $1 \Delta s d c 25 \Delta$ strain expressing Cdc25 ${ }^{\mathrm{R} 1122 \mathrm{D}, \mathrm{K} 1491 \mathrm{E}}$ instead of wild type $\mathrm{Cdc} 25$ 

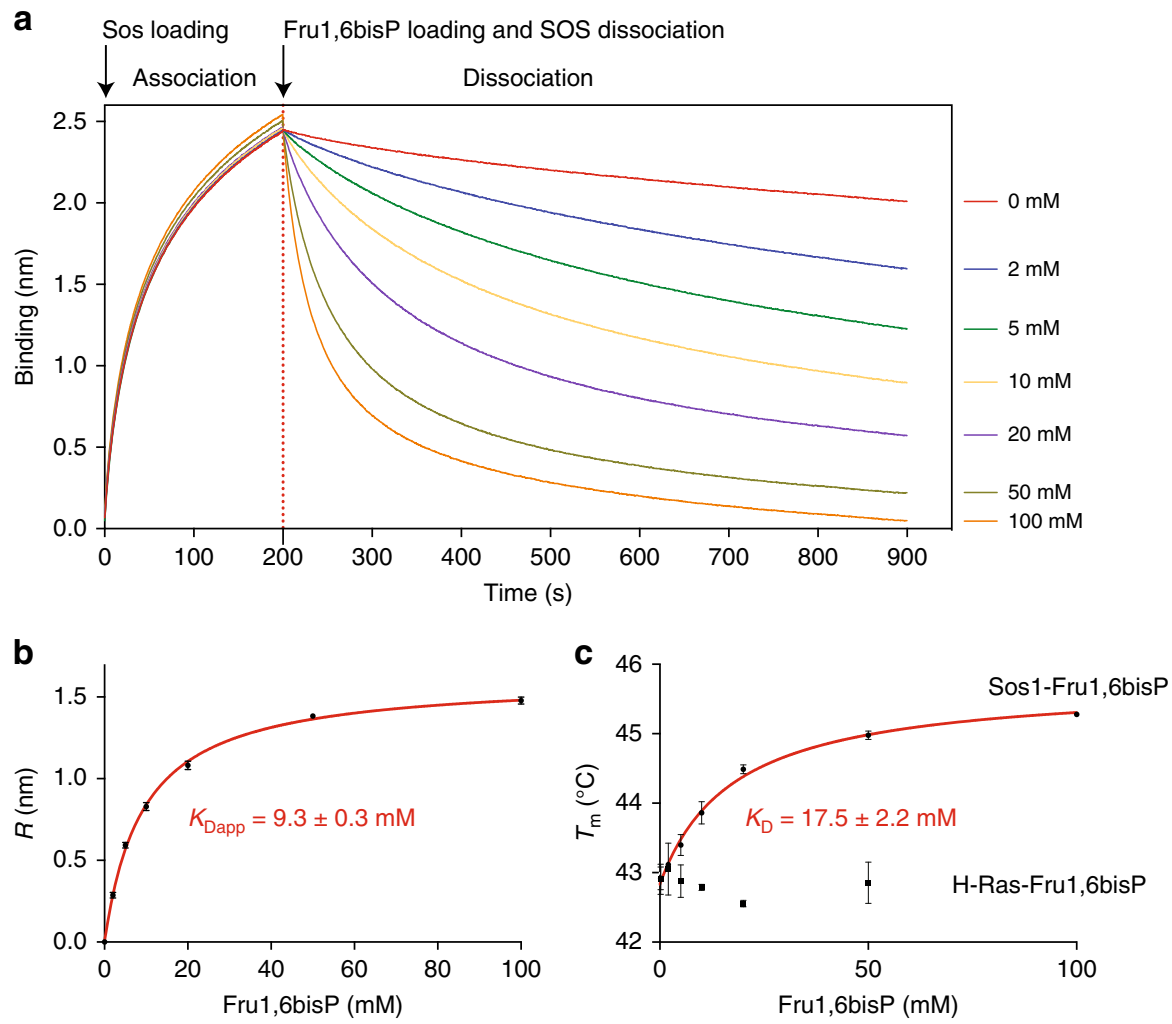

Fig. 7 Fru1,6bisP binds to Sos1 and disrupts the Sos1/H-Ras complex. a, Biolayer interferometry (BLI) measurements showing the disruption of the $\mathrm{Sos} 1 / \mathrm{H}$-Ras complex. His-tagged $\mathrm{H}$-Ras was coupled to $\mathrm{Ni}^{2+}$-coated biosensors and loaded with $0.5 \mu \mathrm{M}$ of non-tagged Sos1 (association phase). Subsequently, dissociation of Sos1 was monitored in buffer containing increasing concentrations of Fru1,6bisP (0, 2, 5, 10, 20, 50, and 100 mM as labeled on the curves). The rates of Sos1 dissociation are dependent on the Fru1,6bisP concentration. $\mathbf{b}$ Titration curve showing the influence of Fru1,6bisP concentration on Sos1/H-Ras complex dissociation. Plotting the BLI signal amplitude as shown in panel a after $150 \mathrm{~s}$ of complex dissociation $(R$; mean $\pm \mathrm{S}$. d.; $n=3$ independent experiments) vs. the Fru1,6bisP concentration yields a binding curve that was fitted on a Langmuir binding model to obtain an apparent $K_{\mathrm{D}}\left(K_{\text {Dapp }}\right)$ value ( \pm s.e.). c Titration curves for binding of Fru1,6bisP to either Sos1 or H-Ras. Melting temperatures ( $T_{\mathrm{m}}$ ) of Sos1 and H-Ras at different ligand concentrations were obtained via thermal shift assays ( $n=3$ independent experiments). Plotting $T_{m}$ values (mean \pm s.d.) vs. ligand concentration yielded binding curves that were fitted on a Langmuir binding model to obtain $K_{\mathrm{D}}$ values $( \pm$ s.e.)

We first mutagenized the positively charged residues R1122 and K1491 in Cdc25 to negatively charged aspartate and glutamate residues, respectively. In addition, we constructed the T1490P allele of Cdc25 in order to disturb the structure of the alpha helix ${ }^{39}$ in this region. In permeabilized spheroplasts of strains expressing Cdc25 $5^{\mathrm{R} 1122 \mathrm{D}, \mathrm{K} 1491 \mathrm{E}}$ or Cdc25 $5^{\mathrm{T} 1490 \mathrm{P}}$ instead of wild-type Cdc25, addition of Fru1,6bisP in a physiological concentration of $5 \mathrm{mM}$ no longer caused activation of Ras as opposed to addition of GTP (Fig. 6b). This indicates that the residues R1122 and K1491 are in some way important for Fru1,6bisP activation of Ras, either because of direct interaction with Fru1,6bisP or maintenance of a proper Cdc25 conformation, and that also the structure of the alpha helix surrounding T1490 is important for a similar reason.

The activity of Sdc25 was assumed negligible since it is repressed during exponential growth in rich media ${ }^{36}$. The strains carrying the Cdc25 mutated alleles in the absence of Sdc25 were viable, showing that the alleles were functional. Interestingly, a tps $1 \Delta$ sdc25 $\Delta$ strain expressing $\mathrm{Cdc} 25^{\mathrm{R} 1122 \mathrm{D}, \mathrm{K} 1491 \mathrm{E}}$ instead of wild-type Cdc25 displayed strong recovery of growth on glucose, supporting the requirement of these residues for Frul,6bisP activation of Ras in vivo (Fig. 6c). We did not observe such recovery of growth on glucose with a strain expressing $\mathrm{Cdc} 25^{\mathrm{T} 1490 \mathrm{P}}$ instead of wild-type Cdc25 (Supplementary Fig. 4a). However, such a strain displayed reduced trehalose and glycogen levels, suggesting the presence of constitutively activated PKA (Supplementary Fig. 4b). This may be explained by $\mathrm{Thr}^{1490}$ serving as a PKA target site for feedback inhibition of PKA on $\mathrm{Cdc} 25$, as previously suggested ${ }^{39}$ or may be due to another effect caused by the distortion of the alfa-helix structure.

Next, we assessed whether human Sos1 expressed in yeast is also responsive to the same type of glycolytic stimulation as yeast Cdc25. Interestingly, addition of Fru1,6bisP in a physiological concentration of $5 \mathrm{mM}$ to permeabilized yeast spheroplasts expressing only the guanine nucleotide exchange factor region of human Sos1 (residues 553-1024), caused a clear activation of Ras similar to that of GTP (Fig. 6d). Wild type Sos1 has the INFSKRR962K sequence. However, the yeast strain expressing the complete Sos1 protein grew poorly on galactose. The mutant protein R962T, which has the same INFSKRTK sequence as in Cdc25, also supported activation of Ras with Fru1,6bisP and GTP (Fig. 6d). The strain expressing this protein showed normal growth on galactose, consistent with the threonine being a target of PKA feedback inhibition. Activation of Ras in permeabilized spheroplasts with Fru1,6bisP, but not GTP, was absent for the mutant alleles Sos $1^{\mathrm{K} 602 \mathrm{E}, \mathrm{K} 963 \mathrm{E}}$ and Sos $1^{\mathrm{R} 962 \mathrm{P}}$ (Fig. 6d), which have the equivalent mutations to those mentioned above for yeast $\mathrm{Cdc} 25^{40}$. The single-mutation K963E did not yet abolish Fru1,6bisP activation of Ras. These results show that Sos1 is able to mediate activation of Ras by Frul,6bisP and that the corresponding amino acid residues or combinations to those in Cdc25 are also important for the activation.

There are several possibilities for the mechanism by which interaction of Fru1,6bisP with $\mathrm{Cdc} 25 / \mathrm{Sos} 1$ might stimulate 
a

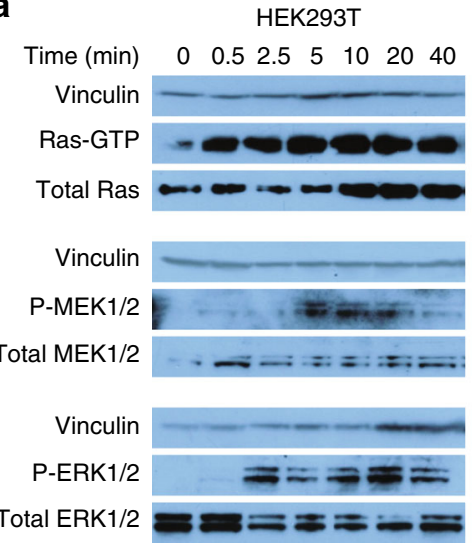

Hela Kyoto

$\begin{array}{lllllll}0 & 0.5 & 2.5 & 5 & 10 & 20 & 40\end{array}$
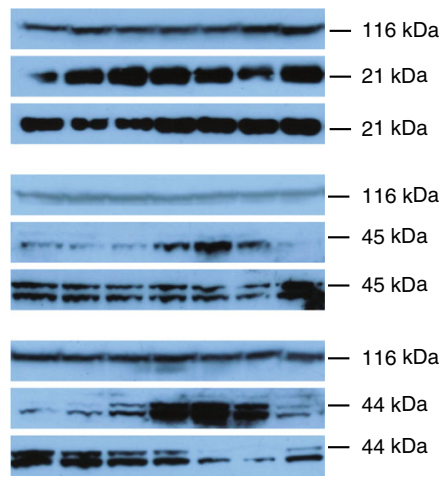
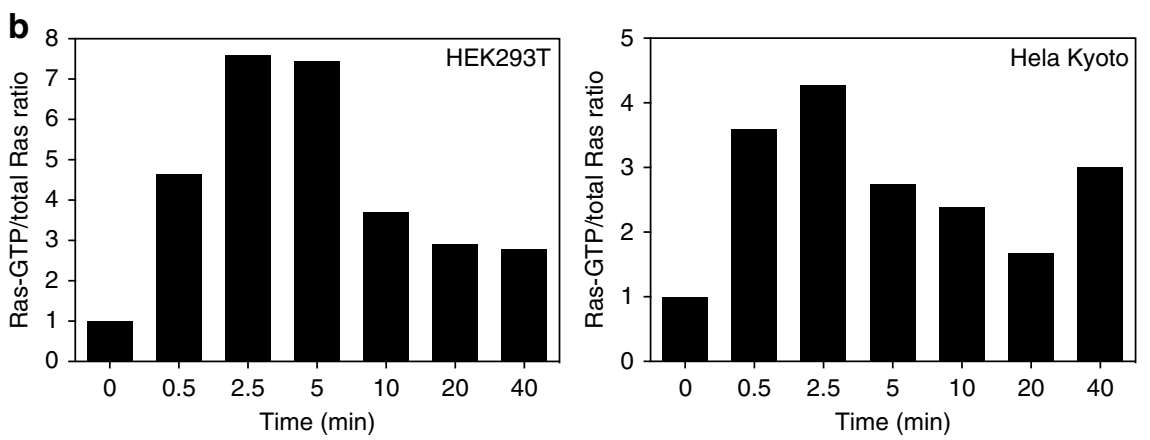

Fig. 8 Addition of glucose triggers activation of the Ras/MEK/ERK pathway in glucose-starved human HEK293T and Hela Kyoto cells. a Western blot analysis of Ras-GTP, P-MEK and P-ERK levels at different time points after glucose addition to HEK293T (left) and Hela Kyoto (right) cells. Samples at time point $\mathbf{O}$ were taken prior to glucose addition. Results are representative for at least three repetitions. $\mathbf{b}$ Quantification of Ras-GTP levels relative to total Ras signals, as depicted in $\mathbf{a}$. All values are expressed relative to that of sample $t=0$, after correction with the vinculin loading control

activation of Ras. It might alleviate one of the limiting steps in the Cdc25/Sos1-Ras nucleotide exchange cycle, for instance the binding of Ras to Cdc25/Sos1, the release of GDP, the incorporation of GTP, the dissociation of Cdc25/Sos1 from Ras or the shielding of Ras from the action of the GTPase activating proteins Ira1,2/NF1.

Fru1,6bisP stimulates dissociation of the Ras/Sos1 complex. To study the interaction of Frul,6bisP with Ras and its Ras GEF factor, we performed an in vitro binding assay (Octet Biolayer interferometry) using human H-Ras (residues 1-166) and the catalytic part of Sos1 (residues 564-1049), and analyzed the effect of Fru1,6bisP on the stability of the Ras/Sos1 complex. First, $\mathrm{H}$-Ras molecules were loaded onto the biosensor, and Sos 1 molecules were allowed to bind to H-Ras during the association phase. Next, the dissociation of the H-Ras/Sos1 complex was monitored in the presence of increasing concentrations of Fru1,6bisP. The biolayer interferometry measurements showed that Fru1,6bisP increases the dissociation rate of the H-Ras/Sos1 complex in a dose-dependent way (Fig. 7a). Plotting of the response (taken $150 \mathrm{~s}$ after addition of Fru1,6bisP) vs. the Fru1,6bisP concentration and fitting yields an apparent $K_{\mathrm{D}}$ $\left(K_{\text {Dapp }}\right)$ of $9.3 \pm 0.3 \mathrm{mM}$ (Fig. $7 \mathrm{~b}$ ), which is in accordance with physiological concentrations of Frul,6bisP in both mammalian and $S$. cerevisiae cells ${ }^{41-43}$. As a control we also tested the effect of addition of glucose, Fru6P, DHAP and GAP. Glucose had no effect on the H-Ras/Sos1 complex, while Fru6P and DHAP produced a very small effect at non-physiological concentrations $\left(K_{\text {Dapp }}=96 \pm 40 \mathrm{mM}\right.$ and $K_{\text {Dapp }}=120 \pm 41 \mathrm{mM}$ for Fru6P and DHAP, respectively; Supplementary Fig. 11). Addition of GAP had no effect on the Ras/Sos 1 complex up to a concentration of 2 $\mathrm{mM}$, but it led to a very fast decrease in signal due to unspecific dissociation of H-Ras from the biosensor at higher concentrations.

We also performed additional biolayer interferometry (BLI) measurements monitoring the disruption of the Sos1/H-Ras complex by different intermediates of glycolysis and GTP (Supplementary Fig. 11). This showed that only Fru1,6bisP and to a lesser extent Fru6P enhanced the rate of Sos1 dissociation.

Fru1,6bisP directly binds to human Sos1. To find out whether the observed disruption of the H-Ras/Sos 1 complex is due to direct binding of Fru1,6bisP to either H-Ras or Sos1, we determined the thermal stability (melting temperature, $T_{\mathrm{m}}$ ) of both proteins in the presence of increasing amounts of Fru1,6bisP, using thermal shift assays ${ }^{44}$. While the thermal stability of H-Ras was quasi unaffected by addition of Fru1,6bisP, the thermal stability of Sos1 increased in the presence of Fru1,6bisP in a dose-dependent way indicating direct binding of Fru1,6bisP to Sos1 (Fig. 7c). Fitting the $T_{\mathrm{m}}$ value vs. the Fru1,6bisP concentration on a Langmuir-binding model yielded a $K_{\mathrm{D}}$ of $17.5 \pm 2.2 \mathrm{mM}$. It should be noted that the latter $K_{\mathrm{D}}$ value corresponds to the real thermodynamic $K_{\mathrm{D}}$ for binding of Fru1,6bisP to Sos1, while the $K_{\text {Dapp }}$ for dissociation of the H-Ras/Sos1 complex also depends on kinetic parameters (rate of complex dissociation).

Glucose activates Ras/MEK/ERK pathway in human cell lines. To assess whether the observed effect of Fru1,6bisP retains physiological relevance in human cells, we studied Ras, MEK, and ERK activation after the addition of glucose to glucose-starved HEK293T and Hela Kyoto cell lines. A $48 \mathrm{~h}$ glucose starvation period lowers the glycolytic flux drastically and thus also the 
Fru1,6bisP level ${ }^{41}$. Re-addition of glucose is known to elevate the intracellular concentration of Fru1,6bisP when glycolysis starts up. The results showed that glucose addition transiently activates Ras, as well as its downstream targets MEK and ERK, both in regular human cells and in cancer cells (Fig. 8a). The ratio of RasGTP over total Ras was quantified for better interpretation (Fig. 8b).

Absence of correlation with proliferation rate. We have also performed multiple experiments to evaluate whether there might be a direct relationship between the proliferation rate of yeast cells, the concentration of Fru1,6bisP and the Ras-GTP level. First, we have measured these three parameters using a series of carbon sources sustaining different proliferation rates. Although there was a tendency for the Ras-GTP level to be lower with lower growth rate, it was certainly not in proportion with the drastically reduced Fru1,6bisP level during growth on non-fermentable carbon sources compared to growth on fermentable sugars (Supplementary Fig. 5). Next, we starved yeast cells for nitrogen on a glucose-containing medium for $50 \mathrm{~h}$ and then re-initiated growth by adding a nitrogen source again. This resulted in a drastic drop in Frul,6bisP and rapid recovery, respectively. However, there was no concomitant change in the level of Ras-GTP at all in the two conditions (Supplementary Fig. 6). We made also use of a yeast strain lacking the PFK26 and PFK27 genes, which encode phosphofructokinase $2^{45}$. It is responsible for the synthesis of Fru2,6bisP, a potent allosteric activator of phosphofructokinase 1 . The double-deletion strain had a strongly reduced level of Fru1,6bisP and a slight reduction in growth rate. However, its Ras-GTP level remained unchanged (Supplementary Fig. 7). Next, we investigated whether the slight reduction in growth rate of the $p f k 26 \Delta p f k 27 \Delta$ strain could be suppressed by an increase in the activity of Ras. The latter was accomplished by single or double deletion of the IRA1 and IRA2 genes ${ }^{37}$ (Supplementary Fig. 8) or by expression of RAS2 $2^{\text {val19 }}$ [10] (Supplementary Fig. 9). However, in none of the two cases was there any increase in the growth rate, neither on glucose nor on galactose medium. All these results indicate that there is no direct relationship between the Fru1,6bisP level and the Ras-GTP level in yeast cells with different proliferation rates. The absence of a clear correlation between Fru1,6bisP and Ras-GTP levels implies that other mechanisms, such as regulation of Ira1,2 activity, must also control the Ras-GTP level. Since yeast strains with constitutively high-Ras activity always showed a tendency for slower growth rates, we overexpressed $R A S 2^{\text {val19 }}$ with a multi-copy vector in different yeast strains. In all cases this led to a dramatic reduction in growth rate on glucose medium (Supplementary Fig. 10). This shows that RAS2 $2^{\text {val19 }}$ is not only toxic under poor growth conditions and in stationary phase, but that very-high expression is also toxic under optimal growth conditions for yeast.

\section{Discussion}

It has been reported that Ras activation stimulates glycolytic rate in tumor cells ${ }^{46,47}$. The opposite signaling effect that we describe here, i.e., activation of Ras by high glycolytic rate through Fru1,6bisP, may close a reciprocal stimulatory signaling loop between cell proliferation and glycolysis. In this regard, increased cytosolic concentrations of Fru1,6bisP have been found in cancer cells $^{42,43}$. Moreover, occurrence of mitochondrial dysfunction, accumulation of ROS and switch from respiration to increased glycolytic activity has also been observed in a mammalian cell system in which the K-Ras(G12V) oncogene was expressed from an inducible promoter ${ }^{48}$. Hence, the reciprocal activation between glycolytic flux and Ras may lock cancer cells in a vicious cycle causing both persistent stimulation of cell proliferation and continued maintenance of overactive glycolysis. This would explain the close correlation between the proliferation rate and aggressive character of cancer cells and their fermentation hyperactivity ${ }^{3,4,49}$. The new regulatory mechanism is consistent with the synthesis of Fru1,6bisP by phosphofructokinase being a major target of metabolic control pathways, oncogene products and tumor suppressor genes in mammalian cells $22,46,47$. It also explains the observation that fructose-1,6-bisphosphatase counteracts carcinoma progression ${ }^{50}$ and that nucleophosmin (NPM1) promotes tumor progression by inhibiting fructose-1,6-bisphosphatase ${ }^{51}$. The similarity between yeast and mammalian cells is further underscored by the finding that in both systems translocation of activated Ras to the mitochondria results in loss of respiratory activity and the appearance of apoptotic markers ${ }^{48,52}$.

Our results show that neither metabolic deregulation, as observed in the tps $1 \Delta$ strain with ras $2 \triangle$ or $p P D E 2$ suppressors, nor the presence of hyperactive Ras, as in a yeast strain expressing Ras $2^{\text {val19 }}$, is by itself enough to trigger apoptosis and absence of growth on glucose. It is apparently the combined presence of metabolic deregulation, or stalled metabolism, and hyperactive Ras that forces the cells into the pathway of programmed cell death. Similar observations have been made with cancer cells in which glucose deprivation triggers apoptosis ${ }^{47}$ and vitamin $\mathrm{C}$ treatment kills $R A S$-oncogene expressing tumor cells, but not wild-type RAS containing cells, by inhibition of $\mathrm{GAPDH}^{53}$. Combined hyperactivation of Ras and inhibition of glycolysis at the level of GAPDH is also observed in the yeast $t p s 1 \Delta$ mutant, in which it is responsible for induction of apoptosis. This combined requirement may help to explain why $R A S$ oncogenes trigger apoptosis only under specific conditions which lead to metabolic deregulation. Another similar mechanism has recently been reported in which Fru1,6bisP directly binds and activates epidermal growth factor receptor (EGFR) causing increased lactate excretion, and EGF signaling activates glycolysis upstream while inhibiting downstream, causing accumulation of intermediates like Fru1,6bis $\mathrm{P}^{54}$.

The Biolayer interferometry (BLI) measurements clearly indicate that Frul,6bisP increases the rate of dissociation of the nucleotide-free Ras-SOS complex. This was unexpected in view of the activating effect of Fru1,6bisP on Ras. Moreover, our results also show that Fru1,6bisP directly binds to SOS1 (and not to Ras). From our results it is hard to pinpoint how exactly this leads to increased activation of Ras in the complex surroundings of the cell. However, it is known that activation of Ras by SOS normally occurs in two steps, where in a first step binding of SOS to GDPbound Ras leads to dissociation of GDP and in a second step binding of GTP to the nucleotide-free Ras-SOS complex leads to dissociation of the complex concomitant with Ras-GTP loading ${ }^{40}$. Increased activation of Ras in a cellular context could potentially occur through increasing the rate of either step. The observed Fru1,6-bisP-induced dissociation of the nucleotide-free Sos-Ras complex might accelerate activation of Ras by acting between these two steps or through another yet to be identified mechanism. Moreover, at least in yeast, the number of Cdc25 molecules is very low compared to the number of Ras molecules ${ }^{55}$. Hence, a second way in which faster dissociation of Cdc25 and Ras may stimulate Ras activity, is that it may make the limited number of Cdc25 molecules more rapidly available for activation of other Ras molecules.

Since Fru1,6bisP is able to chelate $\mathrm{Mg}^{2+56}$, we have considered the possibility that a reduction in the $\mathrm{Mg}^{2+}$ concentration may activate nucleotide exchange on Ras. However, the effect of Fru1,6bisP in the in vitro biophysical experiments is already observed at concentrations much lower than the $10 \mathrm{mM} \mathrm{MgCl}_{2}$ used in the buffer. Also the direct binding of Frul,6bisP on SOS with a $K_{\mathrm{D}}$ in the same range as the Fru1,6bisP concentration 
in vivo and the apparent $K_{\mathrm{D}}$ for Ras-SOS complex dissociation argues against a mere effect of Frul,6bisP as a chelator.

We have also performed multiple experiments to evaluate whether there might be a direct relationship between the proliferation rate of yeast cells, the concentration of Fru1,6bisP and the Ras-GTP level. However, no clear correlation could be found (see Supplementary Figs. 5-10). Hence, although both yeast and mammalian cells show within min rapid glucose-induced activation of Ras and its downstream targets, other mechanisms may intervene in hierarchical control of the cell proliferation rate.

In conclusion, we have identified a direct regulatory connection between Fru1,6bisP in glycolysis and the Ras proteins, that seems to be evolutionary conserved in yeast and mammalian cells. It is responsible for induction of apoptosis in yeast cells with overactive influx of glucose into glycolysis and stalled flux at the level of GAPDH. We suggest that Fru1,6bisP activation of Ras constitutes a key mechanism through which the Warburg effect might stimulate oncogenic potency.

\section{Methods}

Yeast strains and plasmids. All S. cerevisiae strains used in this work are listed in Supplementary Table 1. They all share the same genetic background, i.e. W303. The YEplac195 expression vector contains the promoter and terminator sequences of the $5^{\prime}$ and $3^{\prime}$ regions of the PDE2 gene. The YCpRas $2^{\text {val19 }}$ plasmid contains promoter and terminator sequences of the $5^{\prime}$ and $3^{\prime}$ regions of the RAS2 val19 gene.

Growth conditions. When no selection was required, yeast cells were grown in rich YP $(1 \%(\mathrm{w} / \mathrm{v})$ yeast extract, $2 \%(\mathrm{w} / \mathrm{v})$ bactopeptone) medium, supplemented with $100 \mathrm{mg} / \mathrm{L}$ adenine and either $100 \mathrm{mM}$ glucose, $100 \mathrm{mM}$ galactose, $220 \mathrm{mM}$ ethanol or $325 \mathrm{mM}$ glycerol. In case of selection for the presence of an auxotrophic marker either on a plasmid or in the genome, cells were grown in synthetic medium containing $0.17 \%(\mathrm{w} / \mathrm{v})$ yeast nitrogen base without amino acids, $0.5 \%(\mathrm{w} / \mathrm{v})$ ammonium sulfate, the appropriate amount of the required synthetic 'drop out' amino acid and nucleotide mixture and supplemented with $100 \mathrm{mM}$ glucose, 100 $\mathrm{mM}$ galactose, $220 \mathrm{mM}$ ethanol or $325 \mathrm{mM}$ glycerol. The $\mathrm{pH}$ was adjusted with $4 \mathrm{M}$ $\mathrm{KOH}$ to 5.5 for liquid medium and 6.5 for solid medium. For solid medium, 1.75\% (w/v) agar was added after $\mathrm{pH}$ adjustment. Strains were grown at $30^{\circ} \mathrm{C}$. Liquid cultures were grown under continuous shaking (180 r.p.m.).

\section{Expression and purification of RBD-GST from Escherichia coli. Ras-binding} domain of the Raf1-kinase (RBD) GST-fusion protein was constructed in the pGEX2T-1 expression vector and expressed in the E. coli BL21 strain. Cells were grown for $1 \mathrm{~h}$ at $37^{\circ} \mathrm{C}$ prior to addition of IPTG to a final concentration of $0.3 \mathrm{mM}$ to induce gene expression from the pGEX2T-1 plasmid. Induction lasted for $3 \mathrm{~h}$ at $30^{\circ} \mathrm{C}$. Cells were harvested and washed with ice-cold PBS buffer. Cells were

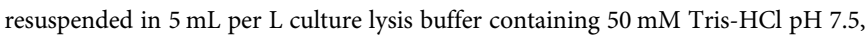
$50 \mathrm{mM} \mathrm{NaCl}, 2 \mathrm{mM}$ EDTA pH 8, $1 \mathrm{mM}$ EGTA pH 8, 20\% sucrose and $5 \mathrm{mg} / \mathrm{mL}$ lysozyme at a concentration of $10 \mathrm{~mL}$ per $\mathrm{L}$ of culture and incubated for at least 15

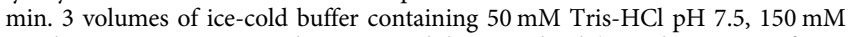
$\mathrm{NaCl}, 1 \%$ Triton X-100 and protease inhibitor cocktail (complete, EDTA-free, Roche) was added. Cells were lysed by sonicating three times for $15 \mathrm{~s}$. Lysates were clarified by centrifugation at 20,000 r.p.m. for $25 \mathrm{~min}$ at $12,000 \times g$. The resulting supernatant fraction was incubated with $2 \mathrm{~mL}$ per $\mathrm{L}$ of initial culture of a 50-50 slurry of glutathione-sepharose beads (GE Healthcare) prewashed with $1 \mathrm{x}$ TBST (50 mM Tris- $\mathrm{HCl} \mathrm{pH} \mathrm{7.5,150} \mathrm{mM} \mathrm{NaCl,} 1 \%$ Triton X-100 and $1 \mathrm{mM} \mathrm{DTT)}$ and incubated for $1 \mathrm{~h}$ in a roller drum at $4{ }^{\circ} \mathrm{C}$. Beads were collected by centrifugation at $1800 \mathrm{rpm}$ for $1 \mathrm{~min}$ and washed 4 times with TBST. Beads were resuspended in TBS (TBST minus Triton) at a final concentration of $10 \%$. The addition of $0.02 \% \mathrm{NaN}_{3}$ allowed keeping this solution for up to 6 months.

Preparation of a yeast crude cell extract. Cells were grown to an OD of 3-4 and collected on a microfilter connected to a vacuum pump. After washing with icecold water, $200 \mathrm{mg}$ cells were collected in a screw cap tube. $0.2 \mathrm{~g}$ of glass beads were added together with $500 \mu \mathrm{L}$ of lysis buffer containing $50 \mathrm{mM}$ Tris- $\mathrm{HCl} \mathrm{pH} \mathrm{7.5,10 \%}$ glycerol, $2.5 \mathrm{mM} \mathrm{MgCl}_{2}, 1 \%$ Igepal (NP-40) and $200 \mathrm{mM} \mathrm{NaCl}$. The cells were broken by shaking three times $20 \mathrm{~s}$ in a fast prep apparatus. A clarified crude protein extract was obtained after 5 min centrifugation at $8000 \mathrm{rpm}$. Protein concentration was measured by mixing $20 \mu \mathrm{L}$ of sample together with $300 \mu \mathrm{L}$ of the Pierce $660 \mathrm{~nm}$ protein measurement buffer and absorbance was measured at 660 $\mathrm{nm}$ using a bovine serum albumin (BSA) standard curve.

Preparation of permeabilized spheroplasts. The protocol for preparation of spheroplasts was adapted from previous reports ${ }^{35,57}$. Strains were grown in 1 L YP galactose to exponential phase $\left(\mathrm{OD}_{600}=2\right)$. The cells were washed with water and resuspended at a concentration of $200 \mathrm{mg} / \mathrm{mL}$ in digestion buffer containing $1.2 \mathrm{M}$ sorbitol, $60 \mathrm{mM}$ potassium phosphate buffer $\mathrm{pH} 7.5\left(\mathrm{~K}_{2} \mathrm{HPO}_{4}+\mathrm{KH}_{2} \mathrm{PO}_{4}\right), 1 \mathrm{mM}$ EDTA $\mathrm{pH} 8,10 \mu \mathrm{L} / \mathrm{mL} \beta$-mercaptoethanol and 100 units/mL lyticase. This cell suspension was incubated at $30^{\circ} \mathrm{C}$ and digestion of the cell walls was followed by the decrease in $\mathrm{OD}_{600}$ for a sample of the spheroplast suspension was treated with $5 \%$ SDS $(10 \mu \mathrm{L}$ spheroplast suspension $+990 \mu \mathrm{L}$ SDS $)$. When $\mathrm{OD}_{600}$ had dropped with $80 \%$ in this assay, the spheroplasts were considered appropriate for use and the lyticase digestion was arrested by addition of four volumes of ice-cold $1.2 \mathrm{M}$ sorbitol solution. Spheroplasts were washed two times with ice-cold $1.2 \mathrm{M}$ sorbito and resuspended in spheroplast buffer containing $1.2 \mathrm{M}$ sorbitol, $0.75 \mathrm{mM}$ EDTA, $2 \mathrm{mM} \mathrm{MgSO}_{4}, 1.8 \mathrm{mM} \mathrm{NaCl}$ and $10 \mathrm{mM}$ potassium phosphate buffer $\mathrm{pH}$ 6.8. A sample was taken of the spheroplast suspension to measure protein concentration. For that purpose, $10 \mu \mathrm{L}$ spheroplast suspension was diluted with $90 \mu \mathrm{L}$ of water and the spheroplasts homogenized by vortexing. Subsequently, $20 \mu \mathrm{L}$ of the resulting solution was mixed with $300 \mu \mathrm{L}$ of the Pierce protein measurement buffer and the protein concentration was determined by measuring OD at $660 \mathrm{~nm}$. The spheroplasts were then diluted with spheroplast buffer to a protein concentration of 2 $\mathrm{mg} / \mathrm{mL}$. To permeabilize the spheroplasts, they were incubated for $10 \mathrm{~min}$ at $30{ }^{\circ} \mathrm{C}$ with $20 \mu \mathrm{L} / \mathrm{mL}$ nystatin.

Ras activation assay. Two different Ras activation assays were used. Ras activation was either studied in vivo upon addition of glucose to galactose-grown cells, or in situ, upon addition of different glycolytic intermediates, which cannot be taken up by intact cells, to permeabilized spheroplasts. The level of Ras-GTP was determined with the RBD-GST pull-down assay, as described previously ${ }^{15}$. The responses in the spheroplast preparations showed some quantitative variability, which is likely due to the elaborate spheroplast preparation protocol, but qualitatively the responses were always comparable.

Ras activation as determined with samples taken in vivo. For the in vivo Ras activation assay, glucose was added to galactose-grown cells and the cells were incubated further for $10 \mathrm{~min}$. Crude cell extracts were prepared and a volume containing $2 \mathrm{mg}$ of total protein was added to the beads bound to RBD-GST and incubated for $1 \mathrm{~h}$ at $4{ }^{\circ} \mathrm{C}$ on a roller drum. After incubation, the beads were washed three times with the lysis buffer used to make the crude extracts. After washing, the beads were dried by removing all liquid with a narrow orifice $30 \mathrm{~g}$ needle. To the dried beads, $20 \mu \mathrm{L}$ of $2 \times$ loading buffer was added. This buffer contains $100 \mathrm{mM}$ Tris- $\mathrm{HCl} \mathrm{pH} \mathrm{8,} 20 \mathrm{mM} \beta$-mercaptoethanol, 4\% SDS, 0.2\% bromophenol-blue and $20 \%$ glycerol. This solution was boiled for $5 \mathrm{~min}$ at $96^{\circ} \mathrm{C}$. A volume with $20 \mu \mathrm{g}$ of total protein was used for the control in which the total Ras content was determined and an equal amount of $2 \times$ loading dye was added and boiled. The samples were then ready for western blotting.

Ras activation in permeabilized spheroplasts (in situ). Glycolytic metabolites and GDP were dissolved in $\mathrm{H}_{2} \mathrm{O}$ to a final concentration of $100 \mathrm{mM}$, except glyceraldehyde-3-phosphate, which was dissolved in a potassium phosphate buffer (because it is only available as a very acidic liquid solution). GTP was dissolved in $\mathrm{H}_{2} \mathrm{O}$ to a final concentration of $20 \mathrm{mM}$. $50 \mu \mathrm{L}$ of the stock solutions was added to 1 $\mathrm{mL}$ permeabilized spheroplasts to obtain a final concentration of $5 \mathrm{mM}$ for the metabolites and GDP and a final concentration of $1 \mathrm{mM}$ for GTP. The spheroplasts were incubated for $3 \mathrm{~min}$ at $30^{\circ} \mathrm{C}$ and after incubation snap frozen in liquid nitrogen. $330 \mu \mathrm{L}$ of a $4 \times$ lysis buffer was added to the frozen spheroplasts. Spheroplast lysis was achieved by simple vortexing and the supernatant was cleared by centrifugation at $8000 \mathrm{rpm}$ for $5 \mathrm{~min}$. Crude extracts were incubated with the RBD-GST beads and further processed as described in the previous section.

\section{Glucose activation of Ras in mammalian and cancer cells. Mammalian} HEK293T cells (ATCC, USA) and Hela Kyoto cancer cells (a kind gift of Dr. D. Gerlich $^{58}$ ), characterized by Short Tandem Repeat profiling, were used at low passage number $(<15)$ immediately after receipt or after resuscitation from early stocks. Mycoplasma contamination was checked bimonthly with Venor Gem Classic kit (Minerva Biolabs). Both cell lines were grown in Dulbecco's Modified Eagle Medium (DMEM) medium without glucose (11966-025, Invitrogen) supplemented with $2 \mathrm{mM}$ glucose (Life Technologies), $20 \mathrm{mM}$ galactose (Sigma), 6 mM L-glutamine (Sigma), $1 \mathrm{mM}$ sodium pyruvate (Invitrogen), 10\% Fetal Calf Serum (FCS, GE Healthcare), 5 mM HEPES buffer (pH 7.2-7.5) (Thermo Fischer Scientific), 100 units/mL penicillin (Sigma) and $100 \mathrm{mg} / \mathrm{mL}$ streptomycin (Sigma), prior to a $48 \mathrm{~h}$ glucose starvation period in the same medium without glucose supplementation. Activation of Ras, MEK and ERK was monitored in cells incubated in DMEM medium without glucose (D5030, Sigma-Aldrich) after supplementation with $20 \mathrm{mM}$ glucose, $5 \mathrm{mM}$ HEPES buffer (pH 7.2-7.5), 10\% FCS, 100 units/mL penicillin and $100 \mathrm{mg} / \mathrm{mL}$ streptomycin, for different time periods $(0.5$, $2.5,5,10,20$ and $40 \mathrm{~min}$ ). Before lysis, cells were washed with ice-cold PBS (Sigma) and collected in lysis buffer (1\% NP40, $50 \mathrm{mM}$ Tris- $\mathrm{HCl}$ (pH 7.4), $150 \mathrm{mM} \mathrm{NaCl}$, $0.5 \mathrm{mM}$ EDTA, $5 \mathrm{mM} \mathrm{MgCl} 2$ and protease/phosphatase inhibitor cocktails (Roche)). Lysates were centrifuged $\left(14,000 \times g, 15 \mathrm{~min}, 4^{\circ} \mathrm{C}\right)$ and the supernatants were prepared for western blot analysis. Active Ras-GTP levels were assessed following pull-down using RBD-GST-fusion protein beads $\left(1 \mathrm{~h}, 4^{\circ} \mathrm{C}\right)$ (see above). 
Western blotting. All samples were boiled for $5 \mathrm{~min}$ at $96^{\circ} \mathrm{C}$ and briefly centrifuged before loading on the electrophoresis gel. Proteins were separated via SDS-PAGE (NuPAGE 4-12\% Bis-Tris gel, Invitrogen) in NuPAGE MOPS SDS running buffer (Invitrogen) at a constant voltage of 150-200 V. After electrophoresis, proteins were transferred onto nitrocellulose membranes (HybondC extra, GE Healthcare) by blotting for $60 \mathrm{~min}$ at $400 \mathrm{~mA}$ in blotting buffer (NuPAGE MOPS SDS running buffer, with $20 \%(\mathrm{v} / \mathrm{v})$ methanol). Aspecific antibody binding was prevented by incubating the membrane in blocking buffer $((5 \%)(w / v)$ BSA in TBSTween buffer (25 mM Tris- $\mathrm{HCl} \mathrm{pH} 8,150 \mathrm{mM} \mathrm{NaCl}, 0.05 \%(\mathrm{v} / \mathrm{v})$ Tween-20)) for $1 \mathrm{~h}$ at room temperature. Subsequently, the blots were incubated overnight at $4{ }^{\circ} \mathrm{C}$ in blocking buffer with the appropriate antibody: yeast Ras2 (Sc-6759, Santa Cruz, 1:1000, goat pAb), Human Ras (anti-Pan-Ras, Calbiochem, OP40-100UG, 1:500 mouse mAb), ERK (anti-p44/42 MAPK (ERK1/2), Cell Signaling Technology, \#9102, 1:1000, rabbit pAb), P-ERK (anti-phospho-p44/42 MAPK (ERK1/2) (T202/ Y204), Cell Signaling Technology, \#9101S, 1:1000, rabbit pAb), MEK (anti-MEK1/2 (L38C12), Cell Signaling Technology, \#4694, 1:1000, mouse mAb, P-MEK (antiphospho-MEK1/2 (S217/221) (41G9), Cell Signaling Technology, \#9154S, 1:1000, rabbit), Vinculin (anti-vinculin, Sigma-Aldrich, V9131, 1:10000, mouse mAb). Subsequently, the blots were washed three times with TBS-Tween buffer and incubated with the appropriate secondary antibody (Sc-2020, Santa Cruz) in TBSTween. After washing three times with TBS-Tween, the membranes were incubated with Supersignal chemiluminescence substrate (Pierce). Proteins were visualized by exposure of the membrane in the LAS4000 mini digital system (Fujifilm). Signals were quantified with Aida software. Uncropped scans of key western blots presented in the main figures are provided in Supplementary Fig. 12.

Metabolite determinations. The cells for the metabolite measurements were obtained by culturing in Complete Synthetic medium with $100 \mathrm{mM}$ galactose to an OD of 2-3. They were harvested by centrifugation and washed two times with 25 $\mathrm{mM} \beta$-morpholinoethanesulfonic acid (MES) $\mathrm{pH}$ 6. After the last wash step, the cells were collected on a filter and weighed. For short-term (up to $10 \mathrm{~min}$ ) measurement of the intracellular concentration of metabolites, the cells were then suspended at a concentration of $75 \mathrm{mg}$ wet weight $/ \mathrm{mL}$ in $25 \mathrm{mM}$ MES buffer and incubated in a waterbath at $30^{\circ} \mathrm{C}$. Samples were taken by quenching $2 \mathrm{~mL}$ of cell suspension in 10 $\mathrm{mL}$ of $60 \%$ methanol at $-40{ }^{\circ} \mathrm{C}^{59}$. For metabolite determination after glucose addition, a final concentration of $100 \mathrm{mM}$ glucose was added to the cells and samples were taken as a function of time by taking $2.5 \mathrm{~mL}$ cell suspension which was quenched in ice-cold methanol. The cells were centrifuged at $-20^{\circ} \mathrm{C}$, at $3000 \mathrm{rpm}$ for $3 \mathrm{~min}$. The supernatant was removed completely by the use of a vacuum pump and resuspended in $500 \mu \mathrm{L}$ of $1 \mathrm{M}$ perchloric acid $\left(\mathrm{HClO}_{4}\right)$. The cells were transferred to a screw cap tube and broken with glass beads in the fast prep apparatus (two times $20 \mathrm{~s}$ at speed setting of 6). $500 \mu \mathrm{L}$ of $1 \mathrm{M} \mathrm{HClO}_{4}$ was added again and the mixture spun down for $4 \mathrm{~min}$ at 12,000 r.p.m., at $4^{\circ} \mathrm{C}$. $250 \mu \mathrm{L}$ was mixed with $10 \mu \mathrm{L}$ thymol blue $(25 \mathrm{mg} / 100 \mathrm{~mL})$ and $50 \mu \mathrm{L}$ of $5 \mathrm{M} \mathrm{K}_{2} \mathrm{CO}_{3}$. The tubes were left open for at least 15 min to make sure all $\mathrm{CO}_{2}$ was released. $200 \mu \mathrm{L}$ was transferred to a new test tube and mixed with $100 \mu \mathrm{L}$ of $1 \mathrm{M} \mathrm{HCl}$ and $10 \mu \mathrm{L}$ of $2 \mathrm{M}$ Tris- $\mathrm{HCl} \mathrm{pH} 7.5$

For long-term (up to $30 \mathrm{~h}$ ) measurement of the intracellular concentration of different metabolites, cells were also grown in Complete Synthetic medium with $100 \mathrm{mM}$ galactose to an OD of 2-3, after which $100 \mathrm{mM}$ glucose was added in the cultures. Samples were taken as a function of time as described for the short-term experiments. At the same times a sample with equal volume was collected by filtration to determine the cell dry weight.

Glucose-6-phosphate and ATP. $50 \mu \mathrm{L}$ of the sample was mixed with $150 \mu \mathrm{L}$ of reaction buffer containing $100 \mathrm{mM}$ Hepes $\mathrm{pH} 7.6,0.8 \mathrm{mg} / \mathrm{mL}$ NADP and $10 \mathrm{mM}$ $\mathrm{MgCl}_{2}$. To measure glucose-6-phosphate the enzyme glucose-6-phosphate dehydrogenase $(\mathrm{G} 6 \mathrm{PDH})$ was added in a concentration of $50 \mu \mathrm{g} / \mathrm{mL}$. The NADPH formed in this reaction was measured at a wavelength of $340 \mathrm{~nm}$. The amount of NADPH determined is directly proportional to the amount of glucose-6-phosphate present in the sample. For ATP determination, hexokinase at a concentration of $100 \mu \mathrm{g} / \mathrm{mL}$ was added together with $0.5 \mathrm{mM}$ glucose. Hexokinase will produce glucose-6-phosphate with the glucose added and the ATP present in the sample and the glucose-6-phosphate will be converted again by G6PDH with the generation of NADPH, that is measured and is directly proportional to the ATP concentration present in the sample.

Fructose-1,6-bisphosphate. $50 \mu \mathrm{L}$ of the sample was mixed with $150 \mu \mathrm{L}$ of reaction buffer containing $100 \mathrm{mM}$ Hepes pH 7.6 and $0.3 \mathrm{mM}$ NADH, $2.5 \mu \mathrm{g} / \mathrm{mL}$ glyceraldehyde-3-phosphate dehydrogenase and $2.5 \mu \mathrm{g} / \mathrm{mL}$ triose phosphate isomerase. For measurement of fructose-1,6-bisphosphate, aldolase was added at a concentration of $100 \mu \mathrm{g} / \mathrm{mL}$ and the consumption of NADH was measured at a wavelength of $340 \mathrm{~nm}$.

Reactive oxygen species. The production of reactive oxygen species (ROS) was assessed using dihydrorhodamine 123 (DHR; Sigma-Aldrich) as described previously ${ }^{60}$. Cells were grown in YP galactose medium until mid exponential phase, a sample was collected and $100 \mathrm{mM}$ glucose was added after which a new sample was taken. $5 \mu \mathrm{g} / \mathrm{mL}$ DHR was added to the cells and incubated for $2 \mathrm{~h}$. ROS production was visualized using fluorescence microscopy (Axioplan 2 imaging, Zeiss).
Annexin staining of phosphatidylserine exposure. Cells were stained using the Annexin-V-FLUOS Staining Kit (Roche) as described previously ${ }^{60}$. After growing cells to mid exponential phase in YP galactose medium, $100 \mathrm{mM}$ glucose was added. After $16 \mathrm{~h}$ the cells were collected, washed with PBS buffer and centrifuged for $5 \mathrm{~min}$ at $200 \times g$. Annexin-V-FLUOS labeling solution was prepared according to the instructions of the manufacturer: $1 \mathrm{~mL}$ of incubation buffer and $20 \mu \mathrm{L}$ of Annexin-V-FLUOS labeling reagent and $10 \mu \mathrm{L}$ of propidium iodide solution. Washed cells were incubated in $100 \mu \mathrm{L}$ of this labeling solution for $15 \mathrm{~min}$ after which the cells were observed in the fluorescence microscope. Annexin-V-FLUOS excitation was performed at $488 \mathrm{~nm}$ and emission was measured at $518 \mathrm{~nm}$. Propidium iodide excitation was performed at $488-540 \mathrm{~nm}$ and emission was measured at $617 \mathrm{~nm}$.

Isolation of mitochondria for cytochrome $\mathbf{c}$ release. The procedure was adapted from a previous report ${ }^{61}$. A $1 \mathrm{~L}$ culture was used for each sample. $100 \mathrm{mM}$ glucose was added to a $1 \mathrm{~L}$ culture after which the culture was incubated for the indicated time. The cells were harvested by centrifugation at $3000 \mathrm{rpm}$ for $10 \mathrm{~min}$ and washed two times with 1.2 M sorbitol. The cells were then resuspended in $5 \mathrm{~mL}$ of digestion buffer per g cells. The digestion buffer contained $1.2 \mathrm{M}$ sorbitol, $60 \mathrm{mM}$ potassium phosphate buffer $\mathrm{pH} 7.5,1 \mathrm{mM}$ EDTA $\mathrm{pH} 8,1 \% \beta$-mercaptoethanol (w/v) and $1 \%$ zymolyase $20 \mathrm{~T}$. The mixture was incubated for $1 \mathrm{~h}$ at $30^{\circ} \mathrm{C}$. The spheroplasts formed were collected by centrifugation for $5 \mathrm{~min}$ at $1500 \times \mathrm{g}$, washed two additional times with $1.2 \mathrm{M}$ sorbitol and resuspended in $3 \mathrm{~mL}$ of ST-Buffer, containing $0.25 \mathrm{M}$ sorbitol, $20 \mathrm{mM}$ Tris- $\mathrm{HCl} \mathrm{pH} 7.5,1 \mathrm{mM}$ EDTA and protease inhibitor cocktail (Roche), per g of cells. The suspension was incubated with agitation at $4{ }^{\circ} \mathrm{C}$ until the spheroplasts were osmotically broken. Cell debris were removed by centrifugation at $2000 \times g$ for $5 \mathrm{~min}$ and the supernatant was again centrifuged at $12,000 \times g$ for $15 \mathrm{~min}$ to precipitate mitochondria. Both the postmitochondrial supernatant (SN) and the pellet (the mitochondrial pellet was resuspended in $0.5 \mathrm{M}$ sorbitol) were used to detect cytochrome c by Western blot analysis as described previously ${ }^{62}$.

Purification of H-Ras and Sos1 (residues 564-1049). The open reading frames, codon optimized for expression in E. coli, for human H-Ras (residues 1-166) and Sos1 (residues 564-1049) were ordered from Genscript, Inc., and cloned into the pET28b vector using the NdeI and XhoI restriction sites (Novagen). His-tagged H-Ras and Sos1 proteins were expressed in E. coli BL21 and purified by immobilized metal ion affinity chromatography (IMAC) and size-exclusion chromatography as described previously ${ }^{40}$. The His-tag was either kept or cleaved off by TEV protease $\left(12 \mathrm{~h}\right.$ at $\left.4{ }^{\circ} \mathrm{C}\right)$, after which the uncleaved protein was removed by a second IMAC.

Biolayer Interferometry (BLI) experiments. Biolayer interferometry measurements were performed using an Octet Red96 (Forte Bio, Inc.) system at $25^{\circ} \mathrm{C}$, shaking at $1000 \mathrm{rpm}$ and in a buffer containing $25 \mathrm{mM}$ Hepes pH 7.5, 0.15 M NaC and $0.01 \mathrm{M} \mathrm{MgCl}_{2}$. To monitor disruption of the H-Ras/Sos1 complex by Fru1,6bisP, in a first step the $\mathrm{Ni}^{2+}$-coated biosensors were equilibrated in buffer and a baseline was collected for $30 \mathrm{~s}$. Subsequently the biosensors were loaded with his-tagged H-Ras at a concentration of $12.5 \mu \mathrm{g} / \mathrm{mL}$. After another baseline acquisition (200 s) Sos 1 (residues 564-1049) was added at $0.5 \mu \mathrm{M}(200 \mathrm{~s})$. Finally, the biosensors were transferred to wells containing buffer supplemented with increasing concentrations of Frul,6bisP and dissociation of the H-Ras/Sos1 complex was monitored for $700 \mathrm{~s}$. All samples were prepared and measured in triplicate. To obtain an apparent dissociation constant (dependent on the dissociation kinetics of the complex) the signal $150 \mathrm{~s}$ after transfer to Fru1,6bisP was plotted vs the Frul,6bisP concentration. The resulting titration curve was fitted on a Langmuir equation. A similar procedure was used to study the effect of Fru6P, DHAP, GAP and glucose on the Ras/Sosl complex.

Fluorescence-based thermal shift assay. Thermal shift assays (TSA) were performed with Sos1 (residues 564-1049) and H-Ras in presence of increasing concentrations of Fru1,6bisP. Thermal unfolding was detected by following SYPRO orange fluorescence using a CFX connect Real-Time PCR System (Bio-Rad). 0.2 $\mathrm{mg} / \mathrm{mL}$ of either protein was combined with 5X SYPRO Orange Protein Gel Stain (Thermo Fisher Scientific) at concentrations of Fru1,6bisP ranging from $0 \mathrm{mM}$ to $100 \mathrm{mM}$, in a final volume of $20 \mu \mathrm{l}$. Fluorescence was measured from $20^{\circ} \mathrm{C}$ to $80^{\circ} \mathrm{C}$ at a rate of $0.5^{\circ} \mathrm{C} / 30 \mathrm{~s}$. All samples were prepared and measured in triplicate. The melting temperatures $T_{\mathrm{m}}$ were determined by fitting the first derivatives of the data using Prism with a Gaussian distribution/Boltzmann sigmoidal equation. The $T_{\mathrm{m}}$ values were plotted vs. the added ligand concentrations and these binding curves were analyzed using Prism and fitted with a Langmuir-binding model.

Reproducibility of the results. All experiments were repeated at least three times with consistent results. 
Data availability. The authors declare that all data supporting the findings of this study are available within the article and its Supplementary Information files and from the corresponding author upon reasonable request.

Received: 7 July 2016 Accepted: 14 August 2017

Published online: 13 October 2017

\section{References}

1. Diaz-Ruiz, R., Uribe-Carvajal, S., Devin, A. \& Rigoulet, M. Tumor cell energy metabolism and its common features with yeast metabolism. Biochim. Biophys. Acta 1796, 252-265 (2009).

2. Warburg, O. On the origin of cancer cells. Science 123, 309-314 (1956).

3. Mathupala, S. P., Rempel, A. \& Pedersen, P. L. Aberrant glycolytic metabolism of cancer cells: a remarkable coordination of genetic, transcriptional, posttranslational, and mutational events that lead to a critical role for type II hexokinase. J. Bioenerg. Biomembr. 29, 339-343 (1997).

4. Weber, G. \& Lea, M. A. The molecular correlation concept of neoplasia. $A d v$. Enzyme Regul. 4, 115-145 (1966).

5. Upadhyay, M., Samal, J., Kandpal, M., Singh, O. V. \& Vivekanandan, P. The Warburg effect: insights from the past decade. Pharmacol. Ther. 137, 318-330 (2013).

6. Thevelein, J. M. \& de Winde, J. H. Novel sensing mechanisms and targets for the cAMP-protein kinase A pathway in the yeast Saccharomyces cerevisiae. Mol. Microbiol. 33, 904-918 (1999).

7. van Dam, T. J., Bos, J. L. \& Snel, B. Evolution of the Ras-like small GTPases and their regulators. Small GTPases 2, 4-16 (2011).

8. van Dam, T. J., Rehmann, H., Bos, J. L. \& Snel, B. Phylogeny of the CDC25 homology domain reveals rapid differentiation of Ras pathways between early animals and fungi. Cell Signal. 21, 1579-1585 (2009).

9. Kataoka, T. et al. Functional homology of mammalian and yeast RAS genes. Cell 40, 19-26 (1985).

10. Broek, D. et al. Differential activation of yeast adenylate cyclase by wild-type and mutant RAS proteins. Cell 41, 763-769 (1985).

11. Gourlay, C. W. \& Ayscough, K. R. Actin-induced hyperactivation of the Ras signaling pathway leads to apoptosis in Saccharomyces cerevisiae. Mol. Cell Biol. 26, 6487-6501 (2006).

12. Barbacid, M. ras genes. Annu. Rev. Biochem. 56, 779-827 (1987).

13. Mbonyi, K., Beullens, M., Detremerie, K., Geerts, L. \& Thevelein, J. M. Requirement of one functional RAS gene and inability of an oncogenic ras variant to mediate the glucose-induced cyclic AMP signal in the yeast Saccharomyces cerevisiae. Mol. Cell Biol. 8, 3051-3057 (1988).

14. Colombo, S. et al. Involvement of distinct G-proteins, Gpa2 and Ras, in glucose- and intracellular acidification-induced cAMP signalling in the yeast Saccharomyces cerevisiae. EMBO J. 17, 3326-3341 (1998).

15. Colombo, S., Ronchetti, D., Thevelein, J. M., Winderickx, J. \& Martegani, E. Activation state of the Ras2 protein and glucose-induced signaling in Saccharomyces cerevisiae. J. Biol. Chem. 279, 46715-46722 (2004).

16. Rolland, F. et al. Glucose-induced cAMP signalling in yeast requires both a G-protein coupled receptor system for extracellular glucose detection and a separable hexose kinase-dependent sensing process. Mol. Microbiol. 38, 348-358 (2000)

17. van Aelst, L., Jans, A. W. \& Thevelein, J. M. Involvement of the CDC25 gene product in the signal transmission pathway of the glucose-induced RAS-mediated cAMP signal in the yeast Saccharomyces cerevisiae. J. Gen. Microbiol. 137, 341-349 (1991).

18. Paiardi, C., Belotti, F., Colombo, S., Tisi, R. \& Martegani, E. The large Nterminal domain of $\mathrm{Cdc} 25$ protein of the yeast Saccharomyces cerevisiae is required for glucose-induced Ras2 activation. FEMS Yeast Res. 7, 1270-1275 (2007).

19. Beullens, M. et al. Studies on the mechanism of the glucose-induced cAMP signal in glycolysis and glucose repression mutants of the yeast Saccharomyces cerevisiae. Eur. J. Biochem. 172, 227-231 (1988).

20. Hers, H. G. The discovery and the biological role of fructose 2,6-bisphosphate. Biochem. Soc. Trans. 12, 729-735 (1984).

21. Herling, A., Konig, M., Bulik, S. \& Holzhutter, H. G. Enzymatic features of the glucose metabolism in tumor cells. FEBS J. 278, 2436-2459 (2011).

22. Yalcin, A., Telang, S., Clem, B. \& Chesney, J. Regulation of glucose metabolism by 6-phosphofructo-2-kinase/fructose-2,6-bisphosphatases in cancer. Exp. Mol. Pathol. 86, 174-179 (2009).

23. Bustamante, E. \& Pedersen, P. L. High aerobic glycolysis of rat hepatoma cells in culture: role of mitochondrial hexokinase. Proc. Natl Acad. Sci. USA 74 3735-3739 (1977).

24. Bustamante, E., Morris, H. P. \& Pedersen, P. L. Energy metabolism of tumor cells. Requirement for a form of hexokinase with a propensity for mitochondrial binding. J. Biol. Chem. 256, 8699-8704 (1981).
25. Wilson, J. E. Isozymes of mammalian hexokinase: structure, subcellular localization and metabolic function. J. Exp. Biol. 206, 2049-2057 (2003).

26. Blazquez, M. A., Lagunas, R., Gancedo, C. \& Gancedo, J. M. Trehalose-6phosphate, a new regulator of yeast glycolysis that inhibits hexokinases. FEBS Lett. 329, 51-54 (1993).

27. Thevelein, J. M. \& Hohmann, S. Trehalose synthase: guard to the gate of glycolysis in yeast? Trends Biochem. Sci. 20, 3-10 (1995).

28. Van Aelst, L. et al. Molecular cloning of a gene involved in glucose sensing in the yeast Saccharomyces cerevisiae. Mol. Microbiol. 8, 927-943 (1993).

29. Neves, M. J. et al. Control of glucose influx into glycolysis and pleiotropic effects studied in different isogenic sets of Saccharomyces cerevisiae mutants in trehalose biosynthesis. Curr. Genet. 27, 110-122 (1995).

30. Hohmann, S. et al. The growth and signalling defects of the ggs 1 (fdp1/byp1) deletion mutant on glucose are suppressed by a deletion of the gene encoding hexokinase PII. Curr. Genet. 23, 281-289 (1993).

31. Petitjean, M., Teste, M. A., Leger-Silvestre, I., Francois, J. M. \& Parrou, J. L. A new function for the yeast trehalose-6P synthase (Tps1) protein, as key pro-survival factor during growth, chronological ageing, and apoptotic stress. Mech. Ageing Dev. 161, 234-246 (2017).

32. Hortner, H. et al. Regulation of synthesis of catalases and iso-1-cytochrome $\mathrm{c}$ in Saccharomyces cerevisiae by glucose, oxygen and heme. Eur. J. Biochem. 128, 179-184 (1982).

33. Sass, P., Field, J., Nikawa, J., Toda, T. \& Wigler, M. Cloning and characterization of the high-affinity cAMP phosphodiesterase of Saccharomyces cerevisiae. Proc. Natl Acad. Sci. USA 83, 9303-9307 (1986).

34. van Heerden, J. H. et al. Lost in transition: start-up of glycolysis yields subpopulations of nongrowing cells. Science 343, 1245114 (2014).

35. Noubhani, A., Bunoust, O., Rigoulet, M. \& Thevelein, J. M. Reconstitution of ethanolic fermentation in permeabilized spheroplasts of wild-type and trehalose-6-phosphate synthase mutants of the yeast Saccharomyces cerevisiae. Eur. J. Biochem. 267, 4566-4576 (2000).

36. Boy-Marcotte, E., Ikonomi, P. \& Jacquet, M. SDC25, a dispensable Ras guanine nucleotide exchange factor of Saccharomyces cerevisiae differs from CDC25 by its regulation. Mol. Biol. Cell 7, 529-539 (1996).

37. Tanaka, K. et al. S. cerevisiae genes IRA1 and IRA2 encode proteins that may be functionally equivalent to mammalian ras GTPase activating protein. Cell 60, 803-807 (1990).

38. Van Aelst, L., Boy-Marcotte, E., Camonis, J. H., Thevelein, J. M. \& Jacquet, M. The C-terminal part of the CDC25 gene product plays a key role in signal transduction in the glucose-induced modulation of cAMP level in Saccharomyces cerevisiae. Eur. J. Biochem. 193, 675-680 (1990).

39. Schomerus, C., Munder, T. \& Kuntzel, H. Site-directed mutagenesis of the Saccharomyces cerevisiae CDC25 gene: effects on mitotic growth and cAMP signalling. Mol. Gen. Genet. 223, 426-432 (1990).

40. Boriack-Sjodin, P. A., Margarit, S. M., Bar-Sagi, D. \& Kuriyan, J. The structural basis of the activation of Ras by Sos. Nature 394, 337-343 (1998)

41. Huberts, D. H., Niebel, B. \& Heinemann, M. A flux-sensing mechanism could regulate the switch between respiration and fermentation. FEMS Yeast Res. 12, 118-128 (2012).

42. Marin-Hernandez, A. et al. Modeling cancer glycolysis. Biochim. Biophys. Acta 1807, 755-767 (2011).

43. Mazurek, S., Zwerschke, W., Jansen-Durr, P. \& Eigenbrodt, E. Metabolic cooperation between different oncogenes during cell transformation: interaction between activated ras and HPV-16 E7. Oncogene 20, 6891-6898 (2001).

44. Niesen, F. H., Berglund, H. \& Vedadi, M. The use of differential scanning fluorimetry to detect ligand interactions that promote protein stability. Nat. Protoc. 2, 2212-2221 (2007).

45. Boles, E., Gohlmann, H. W. \& Zimmermann, F. K. Cloning of a second gene encoding 5-phosphofructo-2-kinase in yeast, and characterization of mutant strains without fructose-2,6-bisphosphate. Mol. Microbiol. 20, 65-76 (1996).

46. Kole, H. K., Resnick, R. J., Van Doren, M. \& Racker, E. Regulation of 6phosphofructo-1-kinase activity in ras-transformed rat-1 fibroblasts. Arch. Biochem. Biophys. 286, 586-590 (1991).

47. Telang, S. et al. Ras transformation requires metabolic control by 6 phosphofructo-2-kinase. Oncogene 25, 7225-7234 (2006).

48. $\mathrm{Hu}, \mathrm{Y}$. et al. K-ras $(\mathrm{G} 12 \mathrm{~V})$ transformation leads to mitochondrial dysfunction and a metabolic switch from oxidative phosphorylation to glycolysis. Cell Res. 22, 399-412 (2012).

49. Lo, C. H., Farina, F., Morris, H. P. \& Weinhouse, S. Glycolytic regulation in rat liver and hepatomas. Adv. Enzyme Regul. 6, 453-464 (1968).

50. Li, B. et al. Fructose-1,6-bisphosphatase opposes renal carcinoma progression. Nature 513, 251-255 (2014).

51. Zhu, Y. et al. NPM1 activates metabolic changes by inhibiting FBP1 while promoting the tumorigenicity of pancreatic cancer cells. Oncotarget 6, 21443-21451 (2015).

52. Leadsham, J. E. et al. Whi2p links nutritional sensing to actin-dependent Ras-cAMP-PKA regulation and apoptosis in yeast. J. Cell Sci. 122, 706-715 (2009). 
53. Yun, J. et al. Vitamin C selectively kills KRAS and BRAF mutant colorectal cancer cells by targeting GAPDH. Science 350, 1391-1396 (2015).

54. Lim, S. O. et al. EGFR signaling enhances aerobic glycolysis in triple-negative breast cancer cells to promote tumor growth and immune escape. Cancer Res. 76, 1284-1296 (2016).

55. Wang, M., Herrmann, C. J., Simonovic, M., Szklarczyk, D. \& von Mering, C. Version 4.0 of PaxDb: Protein abundance data, integrated across model organisms, tissues, and cell-lines. Proteomics 15, 3163-3168 (2015).

56. Nowak, T. \& Lee, M. J. Reciprocal cooperative effects of multiple ligand binding to pyruvate kinase. Biochemistry 16, 1343-1350 (1977).

57. Averet, N., Fitton, V., Bunoust, O., Rigoulet, M. \& Guerin, B. Yeast mitochondrial metabolism: from in vitro to in situ quantitative study. Mol. Cell Biochem. 184, 67-79 (1998).

58. Schmitz, M. H. et al. Live-cell imaging RNAi screen identifies PP2A-B55alpha and importin-betal as key mitotic exit regulators in human cells. Nat. Cell Biol. 12, 886-893 (2010).

59. de Koning, W. \& van Dam, K. A method for the determination of changes of glycolytic metabolites in yeast on a subsecond time scale using extraction at neutral pH. Anal. Biochem. 204, 118-123 (1992).

60. Madeo, F., Frohlich, E. \& Frohlich, K. U. A yeast mutant showing diagnostic markers of early and late apoptosis. J. Cell Biol. 139, 729-734 (1997).

61. Herrmann, J. M., Stuart, R. A., Craig, E. A. \& Neupert, W. Mitochondrial heat shock protein 70, a molecular chaperone for proteins encoded by mitochondrial DNA. J. Cell Biol. 127, 893-902 (1994).

62. Ludovico, P. et al. Cytochrome c release and mitochondria involvement in programmed cell death induced by acetic acid in Saccharomyces cerevisiae. Mol. Biol. Cell 13, 2598-2606 (2002).

\section{Acknowledgements}

We thank Willy Verheyden for technical help with the experiments, Nico Vangoethem for help with preparation of the figures and A. Wittinghofer (Max Planck Institute of Molecular Physiology, Dortmund) for the kind gift of the pGEX4T-1-RBD-GST plasmid. This work was supported by a $\mathrm{PhD}$ fellowship from the Agency for Innovation by Science and Technology (IWT-Flanders) to K.P., F.V.L., D.H., and W.V., by a postdoctoral $\mathrm{F}^{+}$-fellowship from the Research Fund of the KU Leuven to H.Q., and by grants from the Fund for Scientific Research-Flanders, Interuniversity Attraction Poles Network P6/14 and P7/40, and the Research Fund of the KU Leuven (Concerted Research Actions) to J.M.T., and a grant from the Belgian Foundation Against Cancer (FAF-F/ 2016/822) to V.J.

\section{Author contributions}

K.P. and J.M.T. conceived the project, K.P., F.V.L., B.M.B., H.Q., V.J., P.T., W.V., and J.M.T. conceived the experimental approaches, K.P., F.V.L., B.F., B.M.B., H.Q., M.T., D.H., W.V., N.B., and C.B.G.-B. performed the experiments, K.P., F.V.L., B.F., B.M.B. H.Q., V.J., P.T., W.V., and J.M.T. analyzed the data, and K.P., F.V.L., H.Q., W.V. and J.M.T. wrote the manuscript.

\section{Additional information}

Supplementary Information accompanies this paper at doi:10.1038/s41467-017-01019-Z

Competing interests: The authors declare possible competing interests. VIB/LRD has submitted a patent application on the use of the Fru1,6bisP interaction with Sos1 for the development of anticancer drugs ('Activation of Ras by a fructose-1,6-bisphosphate/ guanine nucleotide exchange protein complex.' 26 July 2013. EP 13178157.7. K.P. and J.M.T.). The remaining authors declare no competing financial interests.

Reprints and permission information is available online at http://npg.nature.com/ reprintsandpermissions/

Publisher's note: Springer Nature remains neutral with regard to jurisdictional claims in published maps and institutional affiliations.

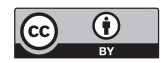

Open Access This article is licensed under a Creative Commons Attribution 4.0 International License, which permits use, sharing, adaptation, distribution and reproduction in any medium or format, as long as you give appropriate credit to the original author(s) and the source, provide a link to the Creative Commons license, and indicate if changes were made. The images or other third party material in this article are included in the article's Creative Commons license, unless indicated otherwise in a credit line to the material. If material is not included in the article's Creative Commons license and your intended use is not permitted by statutory regulation or exceeds the permitted use, you will need to obtain permission directly from the copyright holder. To view a copy of this license, visit http://creativecommons.org/ licenses/by/4.0/.

(C) The Author(s) 2017 